\title{
Do stock markets represent economies?
}

\author{
Dariusz Wójcik \\ Oxford University Centre for the Environment \\ and St.Peter's College Oxford*
}

\begin{abstract}
This paper develops a series of stock market representativeness indices as a new method for analysing stock market development, and applies this method to data on stock markets and economies of thirty-one European countries, as well as Japan and the USA. The main conclusion is that stock markets poorly represent the underlying economies. Publicly traded companies constitute an absolute minority of the total population of large companies. In this respect the level of stock market representativeness in Europe is much lower than in the USA and Japan. Second, in Europe, the USA, and Japan stock markets are strongly biased towards very large companies, towards high technology companies, and particularly high technology knowledge intensive services, as well as towards companies from financial centres. They are biased against smaller, although still large companies, against lower technology manufacturing and less knowledge intensive services, and against provincial companies. Notwithstanding these general findings, stock market representativeness varies considerably between individual countries, highlighting the significance of country-specific factors. Research and development intensity, venture capital industry, asymmetric information, social networks, and government policy are explored as potential reasons for the stock market biases. Implications are drawn for European policy-makers, researchers, as well as financial firms.
\end{abstract}

*Contact details: St.Peter's College, New Inn Hall Street, Oxford OX1 2DL, United Kingdom, Email: dariusz.wojcik@spc.ox.ac.uk.

The author would like to acknowledge the support from Tyrone Bester, Bureau Van Dijk, London, and helpful comments from Gordon L Clark, Adam Dixon, Alan Gilbert, Ashby Monk, Peter Wood and other participants of the seminar held on 16 November 2006 at the University College London. 


\section{Introduction}

Over the last decade European stock markets have witnessed a remarkable development. Since the Investment Services Directive (ISD) came into force in 1996 the equity market capitalisation in the European Union (EU) has tripled and the equity turnover has increased six-fold (Casey and Lannoo 2006). While in the USA and Japan the number of listed companies has stagnated, in the EU it has doubled (ECMI 2006). Considering the achievements of the last decade, and anticipating a new momentum to be provided by the Markets in Financial Instruments Directive (MiFID) replacing the ISD in 2007, the time is appropriate to take stock of the European stock markets. The objective of this paper is to assess the state of the European stock markets, focusing on the issue whether they represent European economies.

Conventionally, the relationship between economies and stock markets is measured with the ratio of market capitalisation to gross domestic product (MC/GDP ratio). This ratio has been the most popular measure of stock market development and one of the principal measures of financial development in general, used frequently in the studies on finance and growth (Rajan and Zingales 2003, Stulz 2005). As a measure of stock or financial market development, however, the MC/GDP ratio has important flaws. First, it is subject to stock market booms and crashes. Between the end of 1999 and the end of 2002 the worldwide market capitalisation was halved, but nobody would suggest that in 2002 stock markets were less developed than three years earlier. Second, the MC/GDP ratio is biased towards companies with large capitalisation. As a result, a country with few very large listed companies would appear to have a more developed stock market than a country with a very large number of relatively small listed companies. While these flaws can be corrected to some extent by using a multi-year average of the $\mathrm{MC} / \mathrm{GDP}$ ratios, and by supplanting the latter with the ratio of the number of listed companies to GDP (or the population size), the MC/GDP ratio also suffers from problems concerning its interpretation.

Consider a recent report of the Scottish Enterprise (2005) evaluating the chances of Scotland becoming an international financial services centre. Drawing a profile of Milan as one of the potential competitors, the report states "Milan stock exchange accounts for $47 \%$ of national GDP" (p.45). An unskilled reader may think that the stock exchange (!) or the stock market contributes $47 \%$ of Italy's GDP, which is obviously wrong. A semiskilled reader may still get an impression that $47 \%$ of the Italian economy is somehow represented on the stock market, which is false too. Only skilled readers would know that the statement means nothing less and nothing more than the MC/GDP ratio for Italy of 0.47. Perhaps trivial at the first glance, this example demonstrates the susceptibility of the MC/GDP ratio to misinterpretation. While deservedly popular among academics, policy-makers, and finance practitioners, the MC/GDP ratio lacks an interpretation illustrating a direct relationship between the stock market and the 'real' economy.

This paper proposes measures focused on stock market representativeness as a way to complement the MC/GDP ratio. A country's stock market is defined as representative if the set of companies listed on stock markets is representative of the broader population of companies operating in the underlying economy in terms of number, size, sector structure, and geography. A series of stock market representativeness indices is developed and applied to data valid for the end of September 2006 for 31 European countries (all European Economic Area countries as of 2007 plus Switzerland), as well 
as Japan and the USA. The results show that only a small fraction of large companies participates in stock markets. In terms of sectors, stock markets are biased towards hightechnology and knowledge intensive services, but intriguingly not so strongly towards high-technology industry. In terms of geography, stock markets are strongly skewed towards companies from financial centres, and against those from the provinces. The results also indicate that countries where closely held companies are more prevalent tend to have less representative stock markets in terms of their sector structure and geography. To be sure, stock market representativeness varies greatly between countries highlighting the significance of country-specific factors in the development of stock markets.

The basic contribution of the paper is to propose easily interpretable indices of stock market representativeness that allow meaningful international comparisons between stock markets. As the analysis of representativeness takes into account a wide range of company characteristics including size, ownership, industry, and geographic location, the paper also contributes to the literature on the economics of listing, including the investigation of reasons why companies go public (see Pagano et al. 1998). The analysis of the geographical representativeness engages with and contributes to the literature on the geography of stock markets and research on investors' home bias at the sub-national level (Coval and Moskowitz 1999). While in his award-winning paper Hau (2001) proved that location matters in equity trading, this paper shows that geography matters also in equity listing. Last but not least, the analysis devoted to ownership structures of listed companies implicates that corporate law and other reforms aimed at more minority-shareholder friendly corporate governance in Europe could also promote more representative stock markets.

In addition to researchers and policy-makers, the findings of the paper should also be useful to financial industry. Stock exchanges and other stock market intermediaries may use representativeness measures to identify parts of the corporate sector that have thus far been underrepresented on stock markets, but could potentially become profitable customers. From investors' perspective, the findings of this paper are significant for three reasons. First, stock market representativeness analysis reminds investors how incomplete their exposure to a country's economy will be, even if they invest in the broadest stock market index available. Second, investors and their analysts could use representativeness measures to filter macroeconomic and business data and establish which is more and which is less relevant for the performance of the stock market. Third, stock market concentrations in terms of the number of issuers, their industry affiliation, and geography, as related to stock market representativeness, can have implications for portfolio volatility and investment risk.

The paper is divided into seven sections. The following section presents the methodology and data used in the construction of three groups of stock market representativeness indices: general, sectoral, and geographical. Sections 3 through to 5 present and analyse the results for each group of indices calculated for 31 European countries, Japan and the USA. Section 6 analyses relationships between indices, and section 7 concludes. 


\section{Indices of stock market representativeness- methodology and data}

In order to measure stock market representativeness the set of companies that participate in the stock markets is compared with the broader population of companies in the underlying economy. There are different degrees of stock market participation. A company can have its shares publicly quoted and traded on an over-the-counter market or listed. Companies can issue new shares through the public stock market and raise funds on the stock market. The highest degree of stock market participation can be considered when a company is widely held with $100 \%$ free float. In this paper, companies participating in the stock markets will be defined as all companies that are publicly listed or at least publicly quoted and traded. A detailed list of each country's market segments covered in the paper is presented in appendix 1. As a result of the broad definition of stock market issuers, the paper covers all alternative, smaller company, and technology focused segments of stock markets. This generous coverage is consistent with the paper's objective to evaluate the representativeness of the public stock market in its entirety.

To assess stock market representativeness it is crucial to carefully delimit the broader population of companies in the underlying economy, to which the set of stock market issuers is compared. It is not possible to consider all enterprises existing in an economy due to the difficulty of obtaining internationally comparable data. Such an approach would also fail to recognise that companies participating in stock markets are relatively large, mainly as a result of fixed costs of stock market participation such as reporting costs as well as initial and ongoing listing fees (Pagano et al. 1998, Oxera 2006). For this reason this paper will compare the set of stock market companies to all companies with turnover in excess of $€ 50 \mathrm{~m}$, adjusted to the price level in a given country, following a formula explained later in this section. The threshold of $€ 50 \mathrm{~m}$ is used officially in the European Union to distinguish between medium and large companies. Companies are assigned to cities and countries where they are headquartered. They are considered as stock market traded, if they are traded on any stock market in the world, not necessarily their home country market. This is to account for the growing numbers of companies that by-pass their domestic stock markets, for example Irish companies listed on the London's Alternative Investment Market, but not on the Irish Stock Exchange.

Thus, the basic idea for measuring stock market representativeness is to compare the set of all issuers participating in stock markets (referred to shortly as publicly traded companies) to all large companies in an economy. On the basis of this idea, three groups of stock market representativeness indices are constructed, and introduced in three separate subsections, which will be followed by the last subsection presenting the data.

\section{General stock market representativeness}

The benchmark general stock market representativeness index (shortly GenRep) is calculated according to the following formula:

(1) GenRep $=\frac{\text { No. of publicly traded companies in a country }}{\text { No. of companies with turnover }>€ 50 \mathrm{~m} \text { in a country }}$ 
The GenRep Index calculates the ratio of the number of publicly traded companies from a given country to the number of companies with turnover in excess of $€ 50 \mathrm{~m}$ (referred to shortly as large companies) in this country. It is treated as the benchmark index because, compared to other indices, it applies the broadest definition of publicly traded companies and the broadest definition of companies in the underlying economies.

The next index PL/AL calculates the fraction of large companies that are publicly traded.

(2) $\mathrm{PL} / \mathrm{AL}=\frac{\text { No. of publicly traded companies with turnover }>€ 50 \mathrm{~m} \text { in a country }}{\text { No. of companies with turnover }>€ 50 \mathrm{~m} \text { in a country }}$

In contrast to the GenRep Index, the PL/AL index does not account for publicly traded companies with turnover smaller than or equal to $€ 50 \mathrm{~m}$, but on the other hand it has a more straightforward interpretation.

The PS/P Index calculates the fraction of companies with turnover smaller than or equal to $€ 50 \mathrm{~m}$ among all publicly traded companies.

(3) $\mathrm{PS} / \mathrm{P}=\frac{\text { No. of publicly traded companies with turnover } \leq € 50 \mathrm{~m} \text { in a country }}{\text { No. of publicly traded companies in a country }}$

The following two indices calculate the fraction of publicly traded companies among all companies with turnover in excess of $€ 200 \mathrm{~m}$ (referred to shortly as very large companies), and among all companies with turnover between $€ 50 \mathrm{~m}$ and $€ 200 \mathrm{~m}$ i.e. large but not very large companies, respectively. The threshold of $€ 200 \mathrm{~m}$ is sensible, since very large companies defined in this way represent approximately $30 \%$ of all large companies in the total sample of 33 countries. If a higher threshold was chosen many small countries would end up with no very large companies at all, thus defeating the purpose of an internationally comparable index.

(4) $\mathrm{PVL} / \mathrm{AVL}=\frac{\text { No. of publicly traded companies with turnover }>€ 200 \mathrm{~m} \text { in a country }}{\text { No. of companies with turnover }>€ 200 \mathrm{~m} \text { in a country }}$

$\mathrm{PML} / \mathrm{AML}=\frac{\text { No. of publicly traded companies with } € 50 \mathrm{~m}<\text { turnover } \leq € 200 \mathrm{~m} \text { in a country }}{\text { No. of companies with } € 50 \mathrm{~m}<\text { turnover } \leq € 200 \mathrm{~m} \text { in a country }}$

Indices defined with formulae (4) and (5) give rise to the Size Bias Index, which calculates the extent to which very large companies are better represented on stock markets than large but not very large companies.

(6) Size Bias $=\frac{\text { PVL/AVL }}{\text { PML/AML }}$

The remaining two indices focus on widely held publicly traded companies, defined as companies with no shareholders owning more than $25 \%$ of shares directly or indirectly. 
The threshold of $25 \%$ is significant, because, as long as one share equals one vote, the definition implies that no single shareholder can block decisions that require $75 \%$ or more of shareholders' votes. While the existing literature uses stricter definitions of a widely held corporation, with thresholds of $20 \%$ or even $10 \%$, and are often based on the structure of actual voting rights rather than shareholdings, the definition used in this paper is dictated by data availability. Nevertheless, as will be demonstrated in section 3 , it produces ratios of widely held firms that correlate extremely well with those found in other studies (La Porta et al. 1996, 1998, 1999, Faccio and Lang 2002).

$\mathrm{PWH} / \mathrm{AL}=\frac{\text { No. of widely held publicly traded companies in a country }}{\text { No. of companies with turnover }>€ 50 \mathrm{~m} \text { in a country }}$

$\mathrm{PWH} / \mathrm{P}=\frac{\text { No. of widely held publicly traded companies in a country }}{\text { No. of publicly traded companies in a country }}$

The index defined with formula (7) is a variation of the GenRep Index, with the numerator restricted to widely held publicly traded companies, while index defined with formula (8) calculates the fraction of widely held among all publicly traded companies.

\section{Sectoral stock market representativeness}

The purpose of the sectoral stock market representativeness index (shortly SecRep) is to capture the difference between the sector structure of publicly traded companies and the sector structure of the underlying economy. The SecRep Index is calculated with the following formula:

(9) SecRep $=1-\frac{\sum_{i=1}^{N}\left|F P_{i}-F A_{i}\right|}{2}$, where:

$F P_{i}$ - no. of publicly traded companies in sector $i$ as a fraction of all publicly traded companies in a country

$F A_{i}$ - no. of companies with turnover $>€ 50 \mathrm{~m}$ in sector $i$ as a fraction of all companies with turnover $>€ 50 \mathrm{~m}$ in a country

$N=58$ sectors according to NACE codes

Calculated in this way, the SecRep Index stands for the fraction of publicly traded companies from a country that would not need to change their sector allocation if their sector structure was to be aligned perfectly with the sector structure of all large companies in this country. In other words, the higher the Index, the more similar the sector structure of publicly traded companies is to the sector structure of large companies. The Index value ranges from $1 /(\mathrm{N}+1)$ to 1 . Calculations were made for 58 sectors according to NACE codes. These codes are used by Eurostat and are the most popular industry classification in European statistics.

\section{Geographical stock market representativeness}

One way to measure geographical stock market representativeness would be to identify regions within countries and compare the regional structure of publicly traded 
companies with that of all large companies. This would, however, involve a difficult task of dividing countries of very different sizes in regions that would then allow meaningful international comparisons. This paper proposes a simplified, but clearer and easier to interpret, notion of geographical stock market representativeness, defined as stock market bias towards companies from the financial centre or centres. This choice is informed by the literature in economics, economic geography, and economic sociology, presenting reasons for and empirical evidence on the advantages enjoyed by central locations in terms of access to financial markets, which will be discussed in section 5 .

The benchmark geographical stock market representativeness index (GeoRep) is calculated with the following formula:

$$
\text { GeoRep }=\frac{\frac{\text { No. of publicly traded companies in the rest of a country }}{\text { No. of companies with turnover }>€ 50 \mathrm{~m} \text { in the rest of a country }}}{\frac{\text { No. of publicly traded companies in the financial centre (-s) of a country }}{\text { No. of companies with turnover }>€ 50 \mathrm{~m} \text { in the financial centre (-s) of a country }}}
$$

The GeoRep Index divides the GenRep Index for the rest of the country by the GenRep Index for the financial centre of the country or the GenRep Index for the major financial centres combined, in case of countries that do not have an obvious single financial centre. In the same way, all other general stock market representativeness indices can be used to construct meaningful geographical representativeness indices. For example, the geographical representativeness index calculated on the basis of PVL/AVL indices, would indicate whether very large companies from the financial centre (-s) are better represented on the stock market than very large companies from the provinces.

Data

Data for the paper were obtained from the ORBIS database, provided by Bureau Van Dijk Electronic Publishing (BDEP). They were harvested by the author in October 2006, but the database was last updated by the BDEP at the end of September 2006. The data were obtained for all 27 European Union member states (including Bulgaria and Romania), Iceland, Liechtenstein, Norway, Switzerland, as well as Japan and the USA, giving a total of 33 countries. The complete coverage of the European Economic Area, including the smallest countries will contribute to robust results, and should make them more useful for European policy-makers.

Data on the numbers of publicly traded companies are valid for the end of September 2006. The data were compared with those available from such sources as the World Federation of Exchanges, the Federation of European Stock Exchanges, and websites of individual stock exchanges. No major discrepancies were detected. The practical reason why the paper could not use a more familiar category of listed companies was that such data were not available in ORBIS. This is, however, not a significant problem, since the objective of the paper is to capture all companies participating in stock markets. In fact, for most countries the number of publicly traded companies as recorded in ORBIS is identical or very similar to the number of listed companies recorded by alternative sources. Data on the number of widely held publicly traded companies are also valid for 
the end of September 2006. They are based on a robust methodology developed by the BVDEP (2006), and are consistent with alternative reputable sources, as discussed in section 3.

Data on the number of companies operating in the underlying economies were collected by filtering companies with turnover in excess of $€ 50 \mathrm{~m}$ and $€ 200 \mathrm{~m}$, respectively, out of all companies included in ORBIS. Turnover figures were based on consolidated financial statements, if available (unconsolidated otherwise), for the last financial year, for which they were available (mostly 2005). The thresholds of $€ 50 \mathrm{~m}$ and $€ 200 \mathrm{~m}$ were adjusted to the country price level, using Eurostat-OECD comparative price levels for 2005, based on the price of a representative basket of consumer goods and services (for details see OECD 2006). The comparative price level for the 30 OECD countries combined is set at 1; indices for individual sample countries in 2005 ranged from 0.40 for Bulgaria to 1.46 for Iceland. The adjusted turnover thresholds were calculated by multiplying $€ 50 \mathrm{~m}$ and $€ 200 \mathrm{~m}$ respectively by a country's comparative price level, and for non-Eurozone countries were translated into domestic currency using the respective Euro exchange rates as at the end of September 2006.

An important issue is whether the ORBIS database captures reliable numbers of all large companies operating in the sample countries. Unfortunately, it is not possible to compare the ORBIS data with those from the Eurostat's New Cronos database, since the latter defines large companies on the basis of the number of employees, not turnover, and the data are often out-of-date and available only for few countries. The use of multiple sources of corporate data by the BVDEP, resulting in impressively high numbers of companies included in ORBIS serves as an important source of assurance. While the numbers of publicly traded companies for European sample countries, Japan, and the USA were $8,646,3,858$, and 8,861 respectively; and the numbers of large companies were 59,300,12,338, and 35,407; the numbers of all companies covered by ORBIS were over 10 million, over 1 million, and nearly 2 million, respectively. Thus, large companies represent less than $1 \%$ of all companies in the ORBIS database. Given that the likelihood of the BVDEP having data on a company grows with the size of the company, the coverage of large companies in the paper should be reliable.

Any analysis comparing numbers of publicly traded companies between countries runs the risk of comparing the incomparable. What counts as a publicly traded company in one country, would not necessarily be recorded as such in another country. Listing rules differ between countries and between stock exchanges. Lenient listing rules can result in high and strict rules in low numbers of recorded issuers. This paper deals with this concern in several ways. First, while the country-specific rules on public stock markets have a direct impact on general representativeness measures such as GenRep, PL/AL, PVL/AVL, and PML/AML, they are not expected to significantly influence other general or the sectoral and geographical representativeness indices, all of which focus on the structures, not numbers of publicly traded companies. Second, indices focused on widely held firms complement other general representativeness measures, as they bring the numbers of publicly traded firms down to a common denominator of dispersed ownership. Third, the paper is transparent about the coverage of publicly traded firms, presented in detail in appendix 1.

In principle, measures of stock market representativeness proposed in this paper could be based on variables other than the raw numbers of companies. Viable alternatives 
include numbers of employees, value-added, turnover or asset values; GDP shares of sectors and regions could be used to calculate sectoral and geographical representativeness; market capitalisation figures could replace the numbers of publicly traded companies. Such alternatives would have the advantage of accounting for the size of companies, and would offer the opportunity to compare stock markets to entire underlying economies, not just large companies. While these constitute avenues for further research, the use of numbers of firms in this paper is justified for several reasons. First, reliable and comparable data on numbers of companies are easier to obtain than data on their characteristics. In addition, company size is to a limited degree accounted for, by using the thresholds of $€ 50 \mathrm{~m}$ and $€ 200 \mathrm{~m}$. More importantly, major questions addressed in this paper can only be answered by using data on numbers of companies. How common are publicly traded companies? What fraction of large companies is publicly traded? What fraction of publicly traded companies is widely held? Are very large companies more likely to be publicly traded than large companies? Are companies from financial centres more likely to be publicly traded than companies from the provinces?

Crucially, the relative advantage or disadvantage of stock market representativeness measures based on numbers of companies depends on the intended use of these measures. This can be illustrated with reference to sectoral representativeness. Corporate finance houses and other intermediaries active on primary markets, and interested in spotting industries underrepresented on stock markets, would use measures based on numbers of companies. In contrast, investors interested in the relationship between the risk-return performance of the stock market and the performance of different sectors of the underlying economy would rather use measures based on market capitalisation and GDP. To summarise, the paper develops the concept of stock market representativeness, accompanied with a wide, comprehensive array of measures, as a useful lens through which to analyse stock markets. However, a single paper cannot exhaust all ways in which this concept can be analysed and applied.

\section{General stock market representativeness}

The values of general stock market representativeness indices are presented in table 1 , accompanied by a map of the GenRep Index in Europe in figure 1. In addition to individual countries, the results in table 1 are presented for three groups of countries, the 'old' EU 15; 10 EU transition countries (8 from 2004, and 2 from 2007 accession); and all 31 European countries covered in the paper, referred to shortly as 'Europe'. Index values for groups of countries were arrived at, not by averaging indices for individual countries, but by adding the respective numbers of companies, and calculating indices on the basis of the resulting totals. This way Europe can be compared to Japan and the USA as a common economic area.

While Germany, France, Italy, and Spain exhibit low, and relatively small economies of Bulgaria, Cyprus, Greece, Iceland, and Slovakia the highest GenRep Index values, there is no significant negative correlation between any of the general representativeness indices and GDP figures for 2005. The GenRep Index varies greatly between countries, from 0.02 in the Czech Republic to 5.92 in Cyprus, which means that in the Czech Republic (Cyprus) there were approximately fifty times more (six times fewer) large companies than publicly traded companies. Among the largest five European 
economies, the UK had the highest GenRep Index. EU 15 and EU transition countries, had a GenRep Index of 0.13 and 0.20 respectively, contributing to the European total of 0.15 , compared to 0.31 in Japan, and 0.25 in the USA.

In every country except Cyprus publicly traded companies constitute an absolute minority of large companies. In Europe only $6 \%$ of large companies are publicly traded. In Europe's largest economies this percentage varies from $7 \%$ in the UK, through $6 \%$ in France and $5 \%$ in Germany, to $3 \%$ in Italy and Spain; and compares unfavourably to $25 \%$ in Japan and $11 \%$ in the USA. In addition, publicly traded companies represent a minority also among very large companies (with the exception of Cyprus and Iceland). In Europe only $11 \%$ of very large companies are publicly traded, $12 \%$ in the UK, $11 \%$ in France, 9\% in Italy and Spain, and 8\% in Germany; compared to 47\% in Japan and $22 \%$ in the USA. While the coverage of publicly traded companies, presented in appendix 1, may suggest that data on Japan and the USA contain more OTC traded companies than data for Europe, it is estimated that in both Japan and the USA these companies represent less than $20 \%$ of the total number of publicly traded companies. Thus, the indices for Japan and the USA, if inflated at all, are not inflated to an extent that would severely affect their comparison with Europe.

Size bias exists for every country except Bulgaria, and Liechtenstein. In the Czech Republic, Ireland, Italy, the Netherlands, Portugal, and Spain companies with turnover exceeding $€ 200 \mathrm{~m}$ are at least five times more likely to be publicly traded than companies with $€ 50 \mathrm{~m}$ to $€ 200 \mathrm{~m}$ in turnover. In transition countries the size bias is lower than in the EU 15. In Europe as a whole and Japan very large companies are approximately three times, and in the USA almost four times more likely to be listed than large but not very large companies.

The share of companies with turnover lower than or equal to $€ 50 \mathrm{~m}$ among all publicly traded firms varies significantly between countries. Not surprisingly, it is high in countries with very high GenRep indices, such as Bulgaria, Cyprus, and Slovakia. Among Europe's largest economies it ranges from $70 \%$ in the UK, through $55 \%$ in France and 53\% in Germany, to $31 \%$ in Spain and 23\% in Italy. For Europe as a whole the share of small and medium firms in stock markets is slightly higher than in the USA, and much higher than in Japan, where it is only 20\%. This indicates that Europe lags behind in terms of general stock market representativeness predominantly because European large and very large companies are much more rarely publicly traded than their counterparts in Japan and the USA.

Indices focused on widely held publicly traded companies demonstrate that the role of the latter differs considerably between countries. The top five countries, with the share of widely held companies over $60 \%$ are the UK, Ireland, Japan, Sweden, and the USA (in this order). Other countries where widely held firms constitute the majority of publicly traded firms are Finland and Switzerland. Not surprisingly widely held companies play a much smaller part in the transition countries than in the EU 15 (Berglöf and Pajuste 2003). However, the rarity of widely held publicly traded companies is not confined to transition economies; in Austria, Cyprus, France, Germany, Austria, Italy, Liechtenstein, and Malta the share of widely held companies is lower than $30 \%$. The indices focused on widely held publicly traded companies will be subject to further scrutiny in the following subsection, where they will be compared to results from the empirical studies on corporate governance and ownership structures. 


\section{Table 1. General stock market representativeness indices}

Index values were calculated by the author according to formulae presented in section 2, based on data from ORBIS provided by the BVDEP. Index values for EU 15, EU Transition 10, and Europe were arrived at by adding the respective numbers of companies, and calculating indices on the basis of the resulting totals, not by averaging indices for individual countries.

\begin{tabular}{|c|c|c|c|c|c|c|c|c|}
\hline Country & GenRep & PL/AL & $P S / P$ & PVL/AVL & PML/AML & Size Bias & $\mathrm{PWH} / \mathrm{AL}$ & $\mathrm{PWH} / \mathrm{P}$ \\
\hline Austria & 0.11 & 0.07 & 0.41 & 0.14 & 0.04 & 3.60 & 0.03 & 0.25 \\
\hline Belgium & 0.08 & 0.04 & 0.45 & 0.09 & 0.03 & 3.32 & 0.02 & 0.30 \\
\hline Bulgaria & 1.61 & 0.12 & 0.92 & 0.11 & 0.13 & 0.88 & 0.42 & 0.26 \\
\hline Cyprus & 5.92 & 0.79 & 0.87 & 1.00 & 0.71 & 1.42 & 0.46 & 0.08 \\
\hline Czech Republic & 0.02 & 0.02 & 0.24 & 0.05 & 0.01 & 6.80 & 0.00 & 0.11 \\
\hline Denmark & 0.16 & 0.07 & 0.55 & 0.12 & 0.05 & 2.47 & 0.08 & 0.49 \\
\hline Estonia & 0.10 & 0.08 & 0.25 & 0.19 & 0.06 & 3.17 & 0.02 & 0.19 \\
\hline Finland & 0.14 & 0.10 & 0.31 & 0.16 & 0.07 & 2.32 & 0.07 & 0.51 \\
\hline France & 0.13 & 0.06 & 0.55 & 0.11 & 0.03 & 3.36 & 0.03 & 0.25 \\
\hline Germany & 0.11 & 0.05 & 0.53 & 0.08 & 0.04 & 1.99 & 0.03 & 0.27 \\
\hline Greece & 0.56 & 0.27 & 0.51 & 0.45 & 0.21 & 2.18 & 0.16 & 0.29 \\
\hline Hungary & 0.07 & 0.04 & 0.43 & 0.09 & 0.02 & 4.71 & 0.01 & 0.22 \\
\hline Iceland & 0.51 & 0.37 & 0.27 & 0.77 & 0.20 & 3.85 & 0.21 & 0.41 \\
\hline Ireland & 0.17 & 0.05 & 0.68 & 0.11 & 0.02 & 6.23 & 0.12 & 0.69 \\
\hline Italy & 0.04 & 0.03 & 0.23 & 0.09 & 0.01 & 6.01 & 0.01 & 0.26 \\
\hline Latvia & 0.30 & 0.08 & 0.74 & 0.20 & 0.06 & 3.60 & 0.05 & 0.18 \\
\hline Liechtenstein & 0.18 & 0.18 & 0.00 & 0.00 & 0.29 & 0.00 & 0.00 & 0.00 \\
\hline Lithuania & 0.32 & 0.21 & 0.33 & 0.37 & 0.17 & 2.12 & 0.04 & 0.12 \\
\hline Luxembourg & 0.19 & 0.10 & 0.47 & 0.18 & 0.05 & 3.85 & 0.06 & 0.33 \\
\hline Malta & 0.24 & 0.11 & 0.55 & 0.13 & 0.11 & 1.16 & 0.02 & 0.09 \\
\hline Netherlands & 0.07 & 0.04 & 0.41 & 0.09 & 0.02 & 5.66 & 0.03 & 0.46 \\
\hline Norway & 0.31 & 0.11 & 0.65 & 0.16 & 0.09 & 1.83 & 0.15 & 0.47 \\
\hline Poland & 0.13 & 0.07 & 0.43 & 0.13 & 0.05 & 2.55 & 0.04 & 0.29 \\
\hline Portugal & 0.09 & 0.05 & 0.37 & 0.14 & 0.02 & 5.88 & 0.03 & 0.36 \\
\hline Romania & 0.11 & 0.06 & 0.45 & 0.09 & 0.05 & 1.63 & 0.01 & 0.06 \\
\hline Slovakia & 0.63 & 0.09 & 0.86 & 0.11 & 0.08 & 1.35 & 0.01 & 0.01 \\
\hline Slovenia & 0.37 & 0.11 & 0.70 & 0.15 & 0.10 & 1.55 & 0.13 & 0.35 \\
\hline Spain & 0.05 & 0.03 & 0.31 & 0.09 & 0.02 & 5.87 & 0.02 & 0.33 \\
\hline Sweden & 0.20 & 0.09 & 0.58 & 0.15 & 0.06 & 2.66 & 0.13 & 0.62 \\
\hline Switzerland & 0.22 & 0.15 & 0.34 & 0.23 & 0.09 & 2.51 & 0.11 & 0.51 \\
\hline UK & 0.22 & 0.07 & 0.70 & 0.12 & 0.04 & 3.00 & 0.16 & 0.70 \\
\hline EU 15 & 0.13 & 0.06 & 0.57 & 0.11 & 0.03 & 3.15 & 0.06 & 0.47 \\
\hline EU Transition 10 & 0.20 & 0.06 & 0.69 & 0.11 & 0.05 & 2.25 & 0.04 & 0.19 \\
\hline Europe & 0.15 & 0.06 & 0.58 & 0.11 & 0.04 & 2.95 & 0.06 & 0.43 \\
\hline Japan & 0.31 & 0.25 & 0.20 & 0.47 & 0.15 & 3.04 & 0.21 & 0.66 \\
\hline USA & 0.25 & 0.11 & 0.55 & 0.22 & 0.06 & 3.73 & 0.14 & 0.55 \\
\hline
\end{tabular}


Figure 1. General Stock Market Representativeness Index (GenRep)

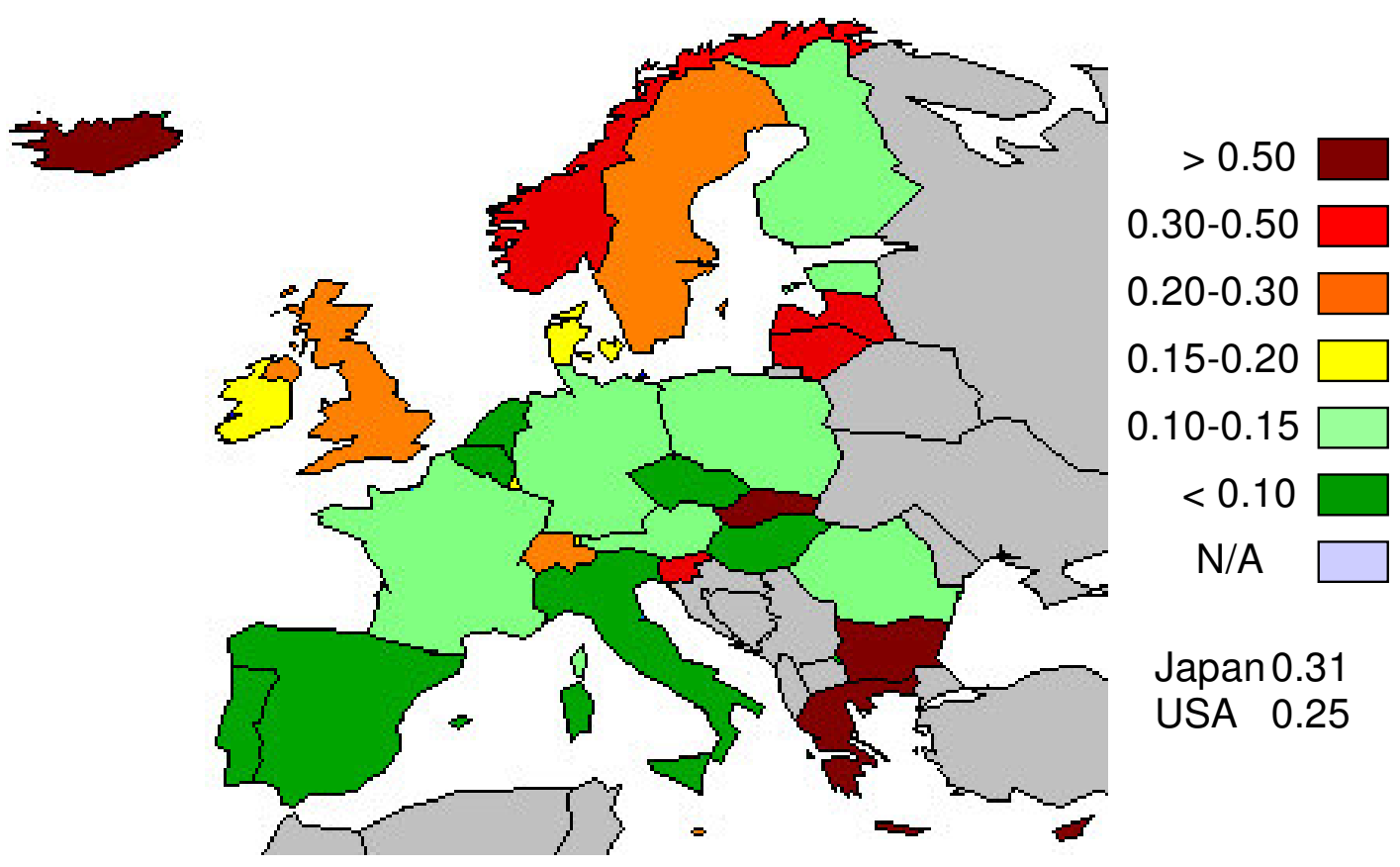

General representativeness indices versus other stock market development measures

As one of the objectives of the paper is to propose stock market representativeness indices as valuable measures of stock market development, this subsection compares general representativeness indices to existing popular measures, presented in appendix 2. The first, and the most popular of them is the MC/GDP ratio, discussed in the introduction. The second measure, labelled 'antidirector rights', was first published by La Porta, Lopez-de-Silanes, Shleifer, and Vishny (LLSV) in 1996 as an index aggregating shareholder rights, measuring "how strongly the legal system favours shareholders (against managers) in the voting process" (La Porta et al. 1996, p.16). ${ }^{1}$ The remaining three measures capture the prevalence of widely held companies among publicly traded companies. 'Fraction of widely held large firms' and 'fraction of widely held medium firms' come from a distinguished paper by La Porta, Lopez-de-Silanes, and Shleifer (LLS), and represent the fraction of widely held firms in the sample of the 20 largest (according to MC at the end of 1995), and 10 smallest publicly traded firms with MC of at least $\$ 500$ million (at the end of 2005), respectively. A firm is considered widely held if it has no shareholder whose total direct and indirect voting rights exceed 20\% (La Porta et al. 1999). The last measure is based on Faccio and Lang (2002, p.379) and presents the percentage of widely held firms among publicly traded firms. While

\footnotetext{
${ }^{1}$ This index was refined in their 1998 paper, ranges from 0 to 6, and is formed by adding one when: (1) the country allows shareholders to mail their proxy vote to the firm; (2) shareholders are not required to deposit their shares prior to a General Shareholders Meeting; (3) cumulative voting or proportional representation of minorities in the board of directors is allowed; (4) and oppressed minorities mechanism is in place; (5) the minimum percentage of share capital that entitles a shareholders to call an Extraordinary Shareholders Meeting is less than or equal to 10\%; and (6) shareholders have pre-emptive rights that can only be waived by a shareholders vote (La Porta et al. 1998, p.1123).
} 
their detailed methodology of studying the ultimate ownership and control differs from that of La Porta et al., a widely held company is also defined as one with no shareholders controlling at least $20 \%$ of voting rights.

The comparison will focus on three selected general stock market representativeness indices: GenRep Index, PWH/AL, and PWH/P. The GenRep is the benchmark index, to be evaluated against the MC/GDP ratio. PWH/AL and PWH/P, focused on widely held companies, can be compared directly to the fractions of widely held firms, and the percentage of widely held firms. The comparison was conducted by calculating rank correlation coefficients between the general representativeness indices and the other measures. In addition, the MC/GDP ratio was correlated with 'antidirector rights', and the variables capturing the prevalence of widely held companies, in order to compare its performance with that of the GenRep Index. Results are presented in table 2. Because the data on 'antidirector rights', 'fraction of widely held large firms', 'fraction of widely held medium firms' are available for 18 non-transition countries only, all correlations for these indices are calculated for 18 countries. In the case of 'percentage of widely held firms', due to the scope of the study by Faccio and Lang, the sample was limited to 13 Western European countries. Correlations for MC/GDP were calculated separately for 23 non- transition and 10 transition countries.

Starting with a direct comparison between the GenRep Index and the MC/GDP ratio, the two are not correlated significantly in non-transition countries, and are negatively correlated in transition countries. As an example, Bulgaria and Slovakia have one of the highest GenRep indices, but the two lowest MC/GDP ratios in the whole sample of 33 countries. In comparison, the Czech Republic, Hungary, and Poland had lower GenRep indices but higher MC/GDP ratios than Bulgaria or Slovakia. The only general stock market representativeness index modestly correlated with MC/GDP ratio in the case of non-transition countries was the $\mathrm{PWH} / \mathrm{P}$ index. These results underscore the distinctive character of the general stock market representativeness indices compared to the MC/GDP ratio.

The remaining four variables of stock market development can be used to further compare the MC/GDP ratio and the general representativeness indices. Antidirector rights show no significant relationship with the MC/GDP ratio, and significant positive relationships with all three general representativeness indices, the strongest in the case of $\mathrm{PWH} / \mathrm{P}$ index. Next, the fraction of widely held large firms is significantly and positively correlated with MC/GDP ratio as well as the general representativeness indices focused on widely held firms. The relationship is stronger for the MC/GDP ratio, because the latter is biased towards large companies. Moving to the fraction of widely held medium companies, it shows positive relationships with MC/GDP ratio and all three general representativeness indices, and the strength of the relationship is almost identical.

Finally, the percentage of widely held firms is again positively and strongly correlated with MC/GDP ratio and all three general representativeness indices. This time, however, the relationship is much stronger for each of the general representativeness indices, than for the MC/GDP ratio. The correlation coefficient reaches as much as 0.94 (significant at $1 \%$ confidence level) for $\mathrm{PWH} / \mathrm{P}$ index. This is not surprising, since the two measures are constructed in a similar way. Both aim at capturing the prevalence of widely held companies among all publicly traded companies. The difference in design 
refers to the definition of a widely held company. While Faccio and Lang apply $20 \%$ of voting rights as a threshold of control, this paper relies on a $25 \%$ threshold of shareholdings. The results are almost perfectly correlated leading to two important observations. First, given the robustness of methods used by Faccio and Lang, the almost perfect correlation confirms the reliability of ownership data from the ORBIS database used in this paper. Second, while Faccio and Lang provide results for 13 Western European countries, this paper does it for 31 European countries as well as Japan and the USA.

Beyond pointing to the usefulness of the $\mathrm{PWH} / \mathrm{P}$ index, the results also support the value of other general representativeness indices. The GenRep and the PWH/AL indices are very different from the MC/GDP ratio. The main information value of the MC/GDP ratio is that it focuses on very large publicly traded companies, 'rewarding' in particular small economies with internationally expansive corporations. As such, Finland, Iceland, Luxembourg, Netherlands, and Sweden all have high, and Switzerland by far the highest MC/GDP ratio in the sample. The GenRep and the PWH/AL indices are insensitive to the size of publicly traded companies, but they reflect much better the fundamental features of a stock market related to corporate governance and ownership structures. An added advantage of general stock market representativeness indices is that they constitute an up-to-date, integrated set of measures, from which users can pick whatever index best suits their analytical needs.

\section{Table 2. Correlations between stock market development and representativeness indices}

The table presents Spearman's rho correlation coefficients for pairs of stock market development and general stock market representativeness indices, and their significance at $5 \%\left({ }^{*}\right)$ or $1 \%\left(^{* *}\right)$ confidence level. Data on GenRep, PWH/AL, and PWH/P are presented in table 1, and those on MC/GDP, antidirector rights, fractions, and percentage of widely held firms are presented in appendix 2 . The data on antidirector rights, fraction of widely held large firms, fraction of widely held medium firms, and percentage of widely held firms are available for selected non-transition countries only, and so all correlations for these indices are calculated for the sample of non-transition countries, with $n=18,18,18$, and 13, respectively. For the sake of comparison, correlations for MC/GDP were calculated separately for non-transition $(n=23)$, and transition $(n=10)$ countries.

Source: Author's calculations based on data from ORBIS provided by the BVDEP; LLSV 1998 and LLS1999; Faccio and Lang 2002; and other sources detailed in appendix 2.

\begin{tabular}{|c|c|c|c|c|c|c|c|c|}
\hline \multirow{2}{*}{$\begin{array}{c}\text { Index } \\
\text { MC/GDP Non-transition }\end{array}$} & \multicolumn{2}{|c|}{$\begin{array}{c}\text { MC/GDP } \\
\text { Non-transition }\end{array}$} & \multicolumn{2}{|c|}{ GenRep } & \multicolumn{2}{|c|}{$\mathrm{PWH} / \mathrm{AL}$} & \multicolumn{2}{|c|}{$\mathrm{PWH} / \mathrm{P}$} \\
\hline & $\mathrm{x}$ & & 0.32 & & 0.30 & & 0.48 & * \\
\hline MC/GDP Transition & $\mathrm{x}$ & & -0.73 & * & -0.18 & & 0.37 & \\
\hline Antidirector rights & 0.40 & & 0.50 & * & 0.56 & * & 0.66 & ** \\
\hline Fraction of widely held large firms & 0.60 & ** & 0.41 & & 0.48 & * & 0.48 & * \\
\hline Fraction of widely held medium firms & 0.55 & * & 0.52 & * & 0.56 & * & 0.56 & * \\
\hline Percentage of widely held firms & 0.59 & * & 0.70 & ** & 0.80 & ** & 0.94 & ** \\
\hline
\end{tabular}




\section{Sectoral stock market representativeness}

Sectoral stock market representativeness index (SecRep) captures the similarity between the sector structure of publicly traded companies and the sector structure of large companies in the underlying economy. It was calculated for 58 sectors according to NACE codes (as amended in 2001, also known as Rev.1.1 NACE codes), the principal statistical classification of economic activities within the European Union. There are different levels of the NACE classification; with 17 groups of activities at the most aggregate level and nearly 700 at the most detailed level. The level selected for the purpose of this paper distinguishes between 62 sectors. All sectors for which there were no companies with turnover exceeding $€ 50 \mathrm{~m}$ were ignored, i.e. private households (code P95), undifferentiated goods (P96), undifferentiated services (P97), and extraterritorial organisations (Q99), leading to the total of 58 analysed sectors. In addition, approx. 1,900 companies for which sector was unknown, representing approx. $2 \%$ of all large companies in the sample, were also removed from the analysis. A detailed list of all sectors is presented in appendix 3.

Figure 2 and table 3 show the SecRep Index by country. Recall, that the index value stands for the fraction of publicly traded companies from a country that would not need to change their sector allocation if their sector structure was to be aligned perfectly with the sector structure of all large companies in this country. In other words, the higher the Index, the more similar the sector structure of publicly traded companies is to the sector structure of large companies. In 17 out of 33 countries the SecRep Index ranges between 0.50 and 0.65. It reaches the highest level in Japan (0.73) and France (0.70). With the five largest economies in Europe all having relatively high SecRep Index values, and transition countries, except Poland, low SecRep Index values, figure 2 suggests that sectoral representativeness may be positively correlated with size. This is true, as the rank correlation coefficient (Spearman's rho) between the SecRep Index and GDP 2005 is 0.52 (significant at 5\% confidence level) for European countries, and 0.32 (significant at $10 \%$ confidence level) for the whole sample. There are however, important exceptions. Relatively small economies of Iceland, Norway, Greece, and Cyprus have stock market sector structures quite similar to the structures of the underlying economies, while the SecRep Index of the USA ranks only $12^{\text {th }}$ in the sample. ${ }^{2}$

\footnotetext{
2 Two methods were considered to ensure that correlation between country size, in terms of GDP, and the SecRep Index is not unduly affected by the specific formula for calculating the latter. First, notice that the use of absolute differences in the formula "punishes" countries with small numbers of publicly traded firms. As an extreme example, imagine a very small country with 1 publicly traded company in the largest sector of the economy, representing $20 \%$ of the total number of companies. While from the perspective of representativeness, the single public company comes exactly from the right sector, the SecRep Index of that country would equal only 0.20 . To correct for this, instead of comparing the sector structure of the underlying economy with the actual structure of the publicly traded companies, the latter could be compared with an implied representative structure of the publicly traded companies. The implied structure would be calculated by allocating the actual total number of publicly traded firms to sectors on the basis of the sector structure of the underlying economy. The allocation would satisfy the condition that the lowest of the ratios for sectors with any publicly traded firms allocated to it (calculated as the percentage share of a given sector in the underlying economy to the number of publicly traded firms allocated to that sector) is at least equal to every percentage share in the underlying economy for sectors without any publicly traded firms allocated to them. Calculations following this procedure produced results very similar to the SecRep Index, and exactly the same ranking of countries, with the sole exception of Liechtenstein. In the light of these results, it does not seem sensible to replace the SecRep
} 


\section{Table 3. Sectoral stock market representativeness}

The table presents the values of the SecRep index, calculated according to formula (9). It also presents the most over- and underrepresented sector for each country, i.e. sector with largest positive (negative) difference between its share in the number of publicly traded firms and its share in the number of large firms. Sector names used here are sometimes shorter versions of full names given in appendix 3. Index values for EU 15, EU Transition 10, and Europe were arrived at by adding the respective numbers of companies, and calculating indices on the basis of the resulting totals, not by averaging indices for individual countries.

\begin{tabular}{|c|c|c|c|}
\hline Country & SecRep & Most overrepresented sector & Most underrepresented sector \\
\hline Austria & 0.54 & Real estate activities & Wholesale and commission trade \\
\hline Belgium & 0.55 & Real estate activities & Wholesale and commission trade \\
\hline Bulgaria & 0.45 & Other business activities & Wholesale and commission trade \\
\hline Cyprus & 0.61 & Activities auxiliary to fin. interm. & Financial intermediation \\
\hline Czech Republic & 0.26 & Electricity, gas, and hot water & Wholesale and commission trade \\
\hline Denmark & 0.44 & Financial intermediation & Other business activities \\
\hline Estonia & 0.31 & Manufacture of food products & Wholesale and commission trade \\
\hline Finland & 0.57 & Computer and related activities & Wholesale and commission trade \\
\hline France & 0.70 & Computer and related activities & Wholesale and commission trade \\
\hline Germany & 0.69 & Computer and related activities & Wholesale and commission trade \\
\hline Greece & 0.67 & Manufacture of textiles & Wholesale and commission trade \\
\hline Hungary & 0.45 & Manufacture of chemicals & Wholesale and commission trade \\
\hline Iceland & 0.67 & Financial intermediation & Retail trade \\
\hline Ireland & 0.50 & Activities auxiliary to fin. interm. & Other business activities \\
\hline Italy & 0.62 & Financial intermediation & Wholesale and commission trade \\
\hline Latvia & 0.47 & Manufacture of other transport & Wholesale and commission trade \\
\hline Liechtenstein & 0.27 & Financial intermediation & Insurance and pension funding \\
\hline Lithuania & 0.58 & Financial intermediation & Wholesale and commission trade \\
\hline Luxembourg & 0.50 & Recreational, cultural and sporting & Wholesale and commission trade \\
\hline Malta & 0.41 & Financial intermediation & Air transport \\
\hline Netherlands & 0.59 & Financial intermediation & Wholesale and commission trade \\
\hline Norway & 0.61 & Computer and related activities & Wholesale and commission trade \\
\hline Poland & 0.64 & Computer and related activities & Wholesale and commission trade \\
\hline Portugal & 0.55 & Recreational, cultural and sporting & Wholesale and commission trade \\
\hline Romania & 0.45 & Manufacture of chemicals & Wholesale and commission trade \\
\hline Slovakia & 0.49 & Manufacture of food products & Wholesale and commission trade \\
\hline Slovenia & 0.54 & Manufacture of food products & Electricity, gas, and hot water \\
\hline Spain & 0.65 & Real estate activities & Wholesale and commission trade \\
\hline Sweden & 0.68 & Computer and related activities & Wholesale and commission trade \\
\hline Switzerland & 0.61 & Financial intermediation & Other business activities \\
\hline UK & 0.64 & Activities auxiliary to fin. interm. & Wholesale and commission trade \\
\hline EU 15 & 0.69 & Activities auxiliary to fin. interm. & Wholesale and commission trade \\
\hline EU Transition 10 & 0.67 & Other business activities & Wholesale and commission trade \\
\hline Europe & 0.71 & Activities auxiliary to fin. interm. & Wholesale and commission trade \\
\hline Japan & 0.73 & Computer and related activities & Wholesale and commission trade \\
\hline USA & 0.61 & Financial intermediation & Wholesale and commission trade \\
\hline
\end{tabular}

Index with a measure involving a less clear formula and interpretation. In addition, the SecRep Index was calculated for 17 instead of 58 sectors, but this again produced similar index values and ranking. 
Figure 2. Sectoral Stock Market Representativeness Index (SecRep)

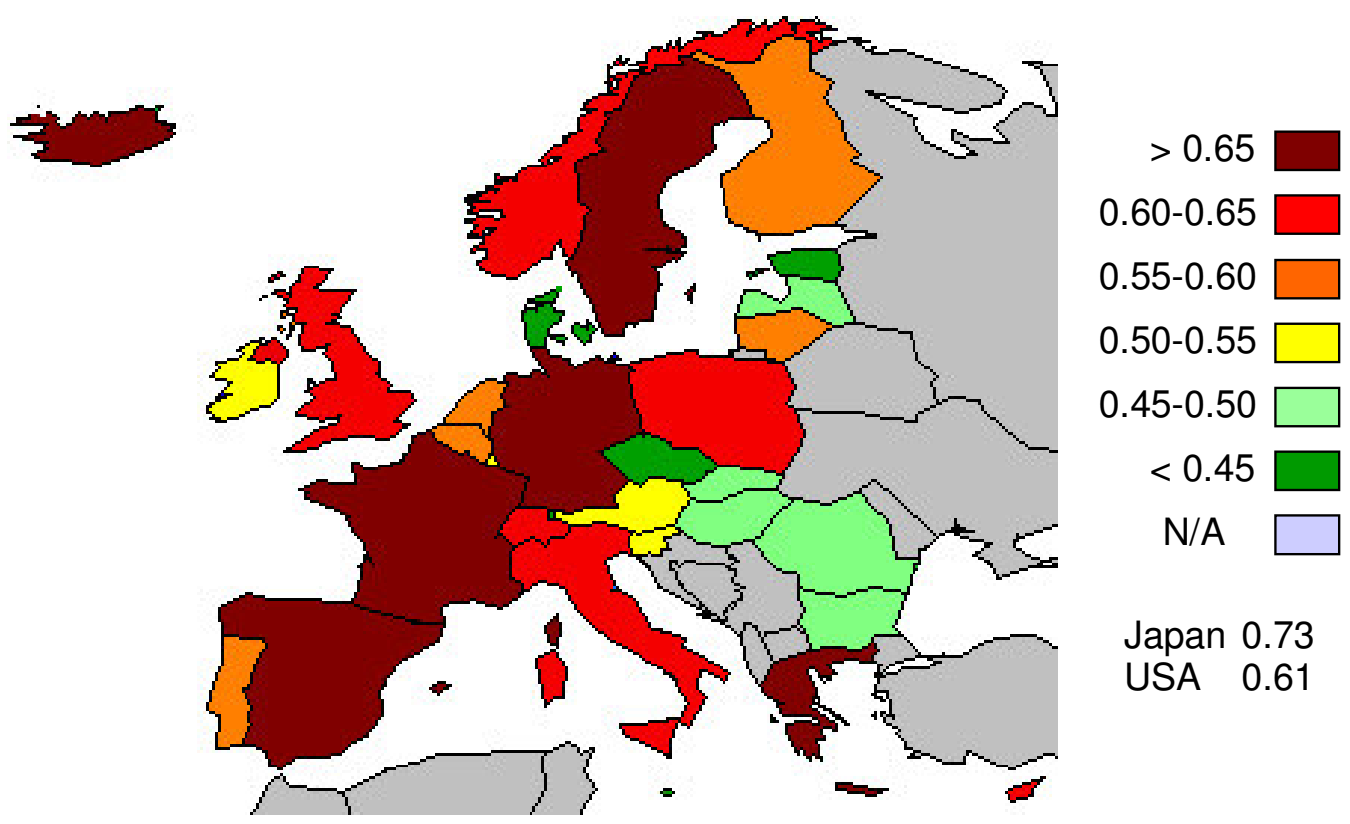

Under- and overrepresented sectors

The focus of the analysis of sectoral representativeness will now shift from countries to specific sectors. Table 3 presents the most over- and underrepresented sector for each country, i.e. sector with largest positive (negative) difference between its share in the number of publicly traded firms and its share in the number of large firms. In addition, appendix 3 for each sector reports the ratio of the number of publicly traded companies to the number of all large companies.

Wholesale and commission trade was the most underrepresented sector in 23 out of 31 European countries, as well as in Japan and the USA. The P/AL ratio for wholesale and commission trade is only 0.06 , compared to 0.20 across all sectors and countries. In Denmark, Ireland, and Switzerland, other business activities (including legal, accounting, tax, advertising, consulting, recruitment services, and call centres) were the most underrepresented sector. The patterns of overrepresentation were more diverse. Financial intermediation except insurance and pension funding (basically banking and leasing) was the most overrepresented sector in 9 countries: Denmark, Iceland, Italy, Liechtenstein, Lithuania, Malta, Netherlands, Switzerland, and the USA; and computer and related activities in 7: Finland, France, Germany, Norway, Poland, Sweden, and Japan. The P/AL ratio was 0.37 and 0.75 for banking and leasing, and computer related services firms, respectively. Real estate was the most represented sector in Austria, Belgium, Spain; and activities auxiliary to financial intermediation (including stock broking and fund management) in Cyprus, Ireland, and the UK. Recreational, cultural, and sporting activities were the most overrepresented sector in Luxembourg and Portugal. In contrast, a manufacturing sector was the most overrepresented sector in five transition economies; manufacturing of food in Estonia, Slovakia, Slovenia, and manufacturing of chemicals in Hungary and Romania. 
In order to investigate the reasons behind over- and underrepresentation of sectors, the fraction of publicly traded firms among all large firms will be analysed by groups of sectors, according to the OECD/Eurostat classification based on their research and development $(R \& D)$ intensity. There are three major considerations underlying such analysis. The first comes from Shleifer and Vishny (1997), who suggested that reliability on equity financing might depend on the role played by intangible assets. As these have low or no liquidation value and low value as collaterals, it may be difficult for intangible asset heavy firms to obtain debt financing. While data on the role of intangible assets in the sample companies are not available, $R \& D$ intensity should serve as a good proxy. Second, it is reasonable to expect that firms with higher R\&D intensity have higher earnings growth potential, and as such can attract higher stock market valuations in terms of the market price to earnings or the market price to book value ratios (Fama and French 1998). Third, as corporate innovations attract publicity, firms with higher R\&D intensity may be more visible to stock market investors and analysts.

The OECD/Eurostat classification divides manufacturing into four, and services into three groups (Eurostat 2006). Its advantage is that it combines the traditional understanding of R\&D intensity, based on technological and tangible innovations, with the concept of knowledge intensity, much more suitable to services than the traditional definition. The allocation of each manufacturing and services sector into the seven groups of the OECD/Eurostat classification is presented in appendix 3. The ratio of the number of publicly traded companies to the number of all large companies in each of these groups is presented in table 4. This ratio is calculated in the same way as the GenRep Index for countries, but since it is calculated for groups of sectors, it is labelled P/AL.

High technology manufacturing has the best representation on stock markets of all manufacturing categories in the USA, Japan, and Western Europe. In the USA, the $\mathrm{P} / \mathrm{AL}$ ratio is as high as 0.87 . Medium high technology manufacturing comes second, in terms of stock market representation, in the USA, and Japan, but in Europe its level of representation is very similar to those of medium low technology and low technology groups. Low technology firms are actually slightly better represented than medium low technology firms in all geographical areas analysed in table 3. Intriguingly, in transition economies, the relationship between R\&D intensity and stock market representation appears reversed, with high technology manufacturing exhibiting the lowest fraction of publicly traded firms.

In contrast to manufacturing, the positive relationship between $\mathrm{R} \& \mathrm{D}$ intensity and stock market representation works perfectly for services. In each country and region presented in table 4, high technology knowledge intensive services have better stock market representation than other knowledge intensive services, and the latter are better represented than less knowledge intensive services. At a more detailed level, not presented in the table, such relationships hold in 17 out of 33 sample countries. In the remaining 16 countries the relationship is limited to less knowledge intensive services having worse stock market representation than either high technology knowledge intensive services or other knowledge intensive services. For comparison, within manufacturing, stock market representation grows in an orderly fashion, as one moves from low, through medium low, and medium high, to high technology, only in Norway, 
Sweden, and the UK. In 22 out of 31 European countries, the high technology manufacturing is not even the best-represented group of manufacturing activities.

To summarise, $R \& D$ intensity appears as a major factor affecting the stock market participation of service companies. Within manufacturing the relationship between R\&D intensity and stock market representation is weaker and varies greatly between countries. In the USA, high and medium high technology manufacturing firms are by far better represented than medium low and low technology firms. In Japan, the level of stock market participation is spread quite evenly across categories of R\&D intensity. Within Europe, high technology manufacturing is best represented in Western Europe, but in transition countries the whole relationship is reversed. These observations can partly explain the relatively low SecRep Index of the USA in relation to some large European countries, and the top level of SecRep Index in Japan. To be sure, the P/AL ratios relate all publicly traded firms, small and large, to large companies in the underlying economies and thus are affected by the distribution of firms by size. This issue, however, does not change the conclusions, since it cannot be expected that the average firm size in a sector is adversely related to its R\&D intensity.

Why does the positive relationship between $R \& D$ intensity and stock market representation for manufacturing hold to a high degree in the USA, to a limited degree in Europe and Japan and not at all in transition economies? A possible explanation is that stock markets in transition economies have not experienced entries of high technology companies to the extent witnessed in Western Europe, not to mention the USA. An important underlying factor is the underdevelopment of the venture capital industry in the transition countries. Recall that within Europe Norway, Sweden, and the UK exhibit a strong relationship between R\&D intensity and stock market representation in manufacturing. Arguably, all these countries have relatively well developed venture capital industry.

Why is the relationship between $R \& D$ intensity and stock market representation so much more consistent for services than manufacturing? Perhaps a venture capital sector is not as important for pushing high technology and knowledge intensive service companies to the stock market, as it is for high technology manufacturing? Maybe in some countries R\&D intensive manufacturing champions are state-controlled and absent from stock markets? Another possible explanation is that the OECD/Eurostat classification for manufacturing does not reflect R\&D intensity as well as their classification for services does? For example, manufacturing of sophisticated pharmaceuticals, and medicinal chemicals is classified as medium high technology while manufacture of all television and radio receivers as high technology. These issues should be addressed by further research. 


\section{Table 4. Stock market representation by groups of activities based on R\&D intensity}

The table reports the values of the P/AL ratio according to the OECD/Eurostat classification of economic activities based on R\&D intensity (Eurostat 2006). The P/AL is the ratio of the number of publicly traded companies to the number of all large companies in a given group of activities, calculated on the basis of ORBIS database provided by the BVDEP. The composition of the OECD/Eurostat groups of activities is presented in detail in appendix 3.

\begin{tabular}{lrrrrrr}
\hline \multicolumn{1}{c}{ OECD/Eurostat group of activities } & EU 15 & $\begin{array}{c}\text { EU } \\
\text { Transition } \\
10\end{array}$ & Europe & Japan & USA & $\begin{array}{c}\text { Total } \\
\text { sample }\end{array}$ \\
\hline High technology manufacturing & 0.37 & 0.18 & 0.36 & 0.58 & 0.87 & 0.61 \\
Medium high technology manufacturing & 0.12 & 0.26 & 0.15 & 0.52 & 0.41 & 0.26 \\
Medium low technology manufacturing & 0.12 & 0.27 & 0.14 & 0.42 & 0.16 & 0.18 \\
Low technology manufacturing & 0.13 & 0.31 & 0.15 & 0.45 & 0.21 & 0.19 \\
& & & & & & \\
High technology knowledge intensive services & 0.46 & 0.42 & 0.48 & 0.81 & 0.81 & 0.64 \\
Other knowledge intensive services & 0.16 & 0.31 & 0.18 & 0.32 & 0.25 & 0.22 \\
Less knowledge intensive services & 0.05 & 0.07 & 0.06 & 0.18 & 0.10 & 0.09 \\
\hline
\end{tabular}

\section{Geographical stock market representativeness}

The geographical stock market representativeness indices capture the extent to which stock markets are biased towards companies from financial centres. They are calculated by dividing the respective general representativeness index for the rest of the country by the value of this index for the financial centre of the country. For six European countries without an obvious single financial centre, the ratios were calculated for two or more major financial centres combined: Berlin, Düsseldorf, Frankfurt am Main, and Munich in Germany; Milan, Rome, and Turin in Italy; Amsterdam and Rotterdam in the Netherlands; Lisbon and Porto in Portugal; Barcelona and Madrid in Spain; Basel, Geneva, and Zürich in Switzerland. As companies are assigned to places where they are headquartered, it is important to carefully delimit the spatial scope of financial centres. The general objective was to treat financial centres as agglomerations, including adjacent urban areas, even if from an administrative point of view they constitute separate cities or townships. For example, the financial centre of France was defined as Ile de France, and that of the USA as the Metropolitan Statistical Area (MSA) of New York - Northern New Jersey - Long Island. Considering the idiosyncratic character of spatial and administrative structures of large cities, details of the financial centres covered, including their spatial scope, are presented in appendix 4.

Table 5 shows the values of the geographical representativeness indices. In 23 out of 33 sample countries the GeoRep and the PL/AL indices are lower than 1 indicating the existence of a stock market bias towards companies from financial centres. Dividing 100 by the PL/AL index and subtracting 100 from the result, one can calculate the percentage advantage of a large firm from the financial centre over a large provincial firm in terms of the likelihood of being publicly traded. In the whole European sample a large company from a financial centre is $34 \%$ more likely to be publicly traded than a large provincial company, in Japan $63 \%$ more likely, and in the USA 15\% more likely. 


\section{Table 5. Geographical stock market representativeness indices}

The geographical stock market representativeness indices capture the extent to which stock markets are biased towards companies from financial centres. They are calculated by dividing the respective general representativeness index for the rest of the country by the value of this index for the financial centre of the country. The GeoRep Index, in particular, is calculated by dividing the ratio of the number of publicly traded companies to the number of companies with turnover in excess of $€ 50 \mathrm{~m}$ in the rest of the country, by the ratio for the financial centre of the country (see formula 10). For six European countries without an obvious single financial centre, the ratios were calculated for two, three or four major financial centres combined. Index values for EU 15, EU Transition 10, and Europe were arrived at by adding the respective numbers of companies, and calculating indices on the basis of the resulting totals, not by averaging indices for individual countries. Indices are marked as not available (n/a) in cases where the denominator equals zero. Details of the financial centres covered, including their spatial scope, are presented in appendix 4. MSA - Metropolitan Statistical Area.

\begin{tabular}{|c|c|c|c|c|c|c|c|c|}
\hline \multirow[b]{2}{*}{ Country - financial centre (-s) } & \multicolumn{8}{|c|}{ Rest of the country / Financial centre (-s) } \\
\hline & GeoRep & PL/AL & $\mathrm{PS} / \mathrm{P}$ & PVL/AVL & PML/AML & $\begin{array}{l}\text { Size } \\
\text { Bias }\end{array}$ & $\mathrm{PWH} / \mathrm{AL}$ & $\mathrm{PWH} / \mathrm{P}$ \\
\hline Austria - Vienna & 0.31 & 0.54 & 0.65 & 0.56 & 0.57 & 0.99 & 0.18 & 0.58 \\
\hline Belgium - Brussels & 0.42 & 0.45 & 0.94 & 0.43 & 0.63 & 0.68 & 0.48 & 1.13 \\
\hline Bulgaria - Sofia & 10.47 & 9.04 & 1.01 & 2.00 & 19.94 & 0.10 & 4.70 & 0.45 \\
\hline Cyprus - Nicosia & 0.42 & 1.13 & 0.89 & 0.75 & 1.23 & 0.61 & 1.03 & 2.42 \\
\hline Czech Republic - Prague & 0.96 & 0.87 & 1.31 & 0.75 & 2.59 & 0.29 & $\mathrm{n} / \mathrm{a}$ & $\mathrm{n} / \mathrm{a}$ \\
\hline Denmark - Copenhagen & 0.53 & 0.63 & 0.83 & 0.64 & 0.83 & 0.77 & 0.53 & 0.99 \\
\hline Estonia - Tallinn & 0.62 & 0.54 & 1.17 & 0.00 & 0.55 & 0.00 & 0.00 & 0.00 \\
\hline Finland - Helsinki & 0.87 & 1.00 & 0.74 & 0.82 & 1.41 & 0.58 & 0.77 & 0.89 \\
\hline France - Paris & 0.59 & 0.54 & 1.07 & 0.63 & 0.69 & 0.91 & 0.35 & 0.60 \\
\hline Germany - 4 centres & 0.46 & 0.60 & 0.81 & 0.79 & 0.50 & 1.57 & 0.34 & 0.74 \\
\hline Greece - Athens & 0.84 & 1.20 & 0.81 & 1.65 & 1.07 & 1.54 & 0.61 & 0.73 \\
\hline Hungary - Budapest & 1.68 & 3.73 & 0.69 & 7.00 & 1.73 & 4.06 & $\mathrm{n} / \mathrm{a}$ & $\mathrm{n} / \mathrm{a}$ \\
\hline Iceland - Reykjavik & 1.48 & 0.00 & 2.00 & $\mathrm{n} / \mathrm{a}$ & 0.00 & $\mathrm{n} / \mathrm{a}$ & 1.27 & 0.86 \\
\hline Ireland - Dublin & 0.63 & 1.13 & 0.60 & 1.20 & 0.84 & 1.43 & 0.60 & 0.95 \\
\hline Italy - 3 centres & 0.57 & 0.65 & 0.59 & 0.88 & 0.71 & 1.24 & 0.52 & 0.90 \\
\hline Latvia - Riga & 3.49 & 3.49 & 1.00 & 3.50 & 3.04 & 1.15 & 1.75 & 0.50 \\
\hline Liechtenstein - Vaduz & 0.00 & 0.00 & $\mathrm{n} / \mathrm{a}$ & $\mathrm{n} / \mathrm{a}$ & 0.00 & $\mathrm{n} / \mathrm{a}$ & $\mathrm{n} / \mathrm{a}$ & $\mathrm{n} / \mathrm{a}$ \\
\hline Lithuania - Vilnius & 3.00 & 1.87 & 2.13 & 2.48 & 2.24 & 1.10 & $\mathrm{n} / \mathrm{a}$ & $\mathrm{n} / \mathrm{a}$ \\
\hline Luxembourg - Luxembourg & 0.18 & 0.30 & 0.38 & 0.53 & 0.00 & $\mathrm{n} / \mathrm{a}$ & 0.10 & 0.58 \\
\hline Malta - Valletta & 0.56 & 0.50 & 1.11 & 0.00 & $\mathrm{n} / \mathrm{a}$ & $\mathrm{n} / \mathrm{a}$ & $\mathrm{n} / \mathrm{a}$ & $\mathrm{n} / \mathrm{a}$ \\
\hline Netherlands - 2 centres & 0.49 & 0.60 & 0.70 & 0.94 & 0.50 & 1.86 & 0.60 & 1.22 \\
\hline Norway - Oslo & 0.83 & 0.90 & 0.97 & 0.69 & 1.36 & 0.51 & 0.73 & 0.89 \\
\hline Poland - Warsaw & 1.00 & 0.88 & 1.19 & 0.80 & 1.25 & 0.64 & 0.89 & 0.89 \\
\hline Portugal - 2 centres & 0.57 & 0.38 & 1.74 & 0.40 & 0.67 & 0.60 & 0.58 & 1.01 \\
\hline Romania - Bucharest & 2.38 & 1.86 & 1.36 & 7.81 & 1.30 & 6.01 & 0.44 & 0.19 \\
\hline Slovakia - Bratislava & 1.66 & 1.96 & 0.98 & 4.00 & 1.59 & 2.51 & $\mathrm{n} / \mathrm{a}$ & $\mathrm{n} / \mathrm{a}$ \\
\hline Slovenia - Ljubljana & 1.30 & 0.99 & 1.13 & 0.91 & 1.05 & 0.87 & 1.43 & 1.10 \\
\hline Spain - 2 centres & 0.42 & 0.67 & 0.70 & 0.61 & 1.36 & 0.45 & 0.43 & 1.02 \\
\hline Sweden - Stockholm & 0.70 & 0.82 & 0.90 & 0.77 & 1.08 & 0.72 & 0.63 & 0.90 \\
\hline Switzerland - 3 centres & 1.41 & 0.93 & 2.90 & 1.07 & 0.87 & 1.23 & 1.17 & 0.83 \\
\hline UK - London & 0.55 & 0.79 & 0.84 & 0.90 & 0.82 & 1.10 & 0.60 & 1.09 \\
\hline EU 15 - all centres & 0.57 & 0.70 & 0.85 & 0.76 & 0.83 & 0.92 & 0.53 & 0.93 \\
\hline EU Transition 10 - all centres & 1.52 & 1.25 & 1.09 & 1.23 & 1.42 & 0.87 & 1.03 & 0.68 \\
\hline Europe - all centres & 0.66 & 0.75 & 0.92 & 0.79 & 0.88 & 0.90 & 0.57 & 0.86 \\
\hline Japan - Tokyo & 0.60 & 0.61 & 0.91 & 0.86 & 0.61 & 1.41 & 0.56 & 0.93 \\
\hline USA - New York MSA & 0.82 & 0.87 & 0.94 & 1.04 & 0.76 & 1.38 & 0.91 & 1.10 \\
\hline
\end{tabular}


Figure 3. Geographical Stock Market Representativeness Index (GeoRep)

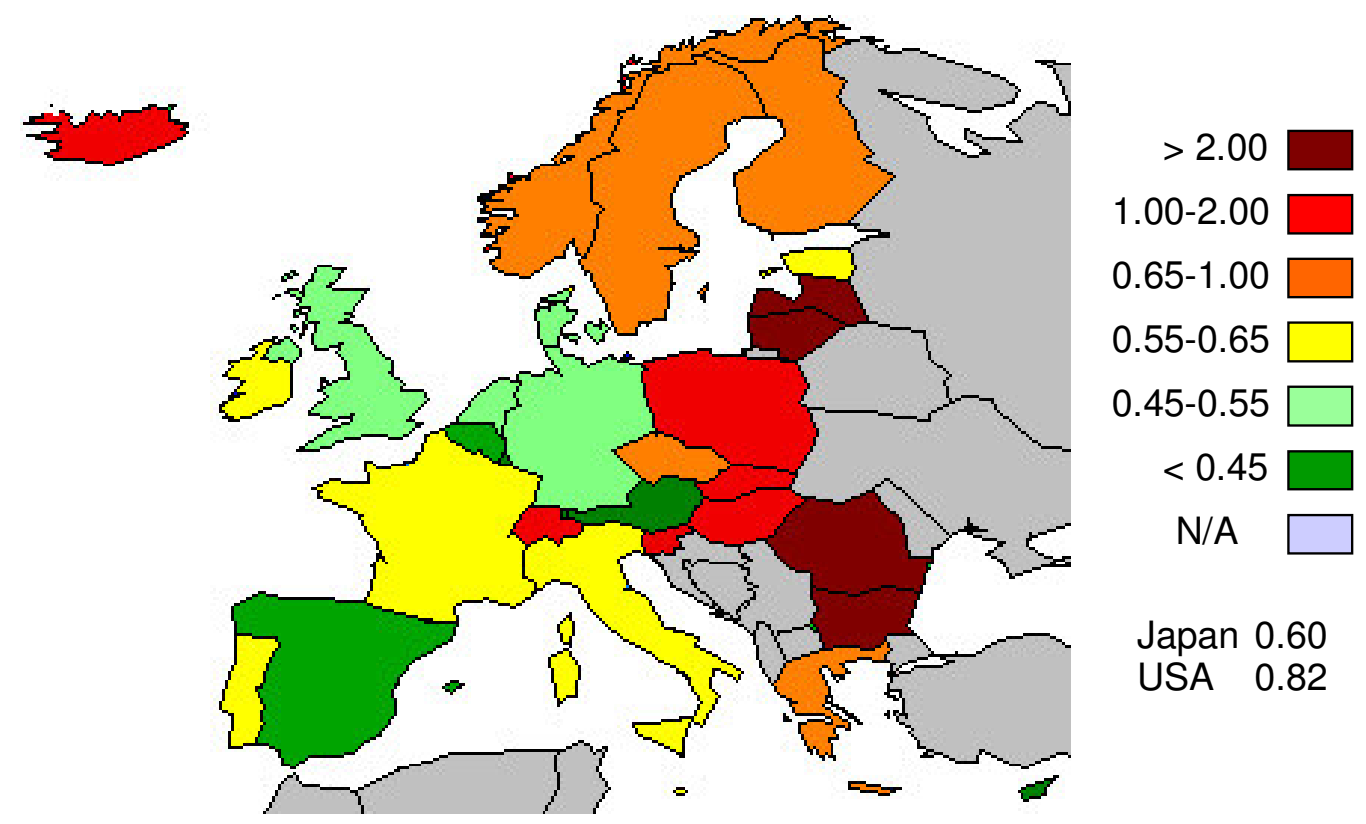

The financial capital bias varies greatly between European countries, and exhibits no significant correlation with the size of the economy. Within the five largest economies it ranges from 26\% in the UK, through $49 \%$ in Spain, 54\% in Italy, and 68\% in Germany, to $86 \%$ in France. In Belgium, Luxembourg, Malta, and Portugal, large firms from financial centres are at least twice more likely to be publicly traded than their provincial counterparts. Figure 3, presenting the GeoRep Index, indicates two important regional patterns, with Nordic countries (except Denmark), and transition countries (except Estonia) exhibiting low or no financial capital bias. In six transition economies, large provincial firms are actually more likely to be publicly traded than large firms from financial centres. The relatively high GeoRep and PL/AL indices for transition economies may be due to the fact that after the fall of communism stock exchanges in these countries were developed and at least until recently owned by the governments. It is sensible to expect, and is confirmed by the author's research in Poland (Wójcik 2007), that reaching potential issuers in different parts of the country have been an important objective of the capital market development policy in these countries.

Other geographical representativeness indices allow further insight into the financial centre bias. In Europe as a whole, Japan, and the USA the share of small firms (equal or less than $€ 50 \mathrm{~m}$ in turnover) in the total number of publicly traded firms is lower in the provinces than in the financial centres. According to PVL/AVL indices, in most countries the likelihood of very large provincial companies being publicly traded is not higher than that of their counterparts in financial centres. Moving to the Size Bias index, being very large, in relation to being large but not very large, increases the likelihood of being publicly traded in Japan and the USA, but in Europe the evidence is mixed. Finally, the PWH/AL and PWH/P indices tend to be lower than one, and indicate that publicly traded widely held companies are less prevalent in the provinces than in financial centres. However, the results differ between countries. In particular, the share of widely held firms in the total number of publicly traded firms is lower in the 
provinces than in the financial centres in France, Germany, and Italy, but higher in the UK and the USA. This leads to an important observation. Financial centres are concentrations of publicly traded companies not just because they host high numbers of headquarters of large companies. Rather, there is something about financial centres that makes small and large companies headquartered there more likely to be publicly traded.

The finding about the financial centre bias contributes to the literature on the role of geography in stock markets. Inspired by the well-documented 'home bias' in international investments (Kang and Stulz 1997, Portes et al. 2001), many researchers have investigated the existence and the nature of a 'local bias', at the sub-national level. Coval and Moskowitz (1999) demonstrate that investment managers in the USA exhibit a strong preference for investing in the stocks of locally headquartered firms, which they ascribe to information advantages of local over non-local investors. Huberman's case study (2001) shows that shareholders of a Regional Bell Operating Company in the USA tend to live in the area served by the company. Grinblatt and Keloharju (2001) confirm that the 'familiarity breeds investment' principle works at the sub-national level, proving that investors, particularly individuals, are "more likely to hold, buy, and sell the stock of Finnish firms that are located close to the investor, that communicate in the investor's native tongue, and that have chief executives of the same cultural background" (p.1053). From a different perspective, Malloy (2005) finds that equity analysts in the USA that are geographically proximate to the analysed companies are more accurate in their forecasts and recommendations than other analysts. The evidence on the existence of 'local bias' is not however universal and equivocal. In his awardwinning paper, Hau (2001), for example, shows that in the trading of the largest German blue chip stocks, traders located in Frankfurt possessed no advantage over traders located elsewhere in Germany, even though German traders as a whole had better performance than foreign traders.

While existing research on the 'local bias' refers to investors, analysts, and traders, to the best knowledge of the author of this paper, it has not yet been applied to primary stock markets. It has been documented that geography matters for listing at the international level. Sarkissian and Schill (2004) demonstrate that geographical and cultural proximity are one of the determinants affecting the choice of overseas venues by cross-listing companies. But does location within a country matter for whether a company participates in the public stock market or not?

This section provides a positive answer to the above question. While it cannot provide a formal analysis of the reasons underlying the financial centre bias of stock markets, some possible explanations can be suggested. First, assuming (i) that primary stock market intermediaries that assist issuers in entering the stock market are strongly concentrated in financial centres, and (ii) that they possess better information about potential issuers that are geographically proximate, they would find provincial companies more risky than their counterparts from the financial centre. Second, potential issuers in financial centres, where by definition there are already many publicly traded companies as well as stock market intermediaries, would have more opportunities to learn about other firms' experiences of going and being public, which in consequence could lower their costs of participating in the public stock markets as well as the risks involved. Third, executives of provincial firms may be more biased against the participation in public stock markets, identifying the latter with the world of 'high-finance' or 'financial high society' to which they do not feel they belong. Thus, 
the potential reasons for the financial centre bias involve geography and economics, but also culture, psychology, and sociology (compare Hong et al. 2004; Preda and Knorr Cetina 2005). Note, that these reasons may also apply to companies that are publicly traded only on a foreign market. Location in a financial centre could make it more likely that a potential or existing issuer is 'picked up' by an international or foreign stock market intermediary, interacts with companies already listed abroad, and is more familiar with the practicalities of international finance.

The findings of this paper are important, because it extends research on 'local bias' to primary stock markets, but also because of its comprehensive empirical coverage. Most existing studies use data on one country at a time, with an absolute majority of research focused on the USA. In contrast, this paper identifies financial centre bias in the USA, Japan, and 21 large and small European economies. To be sure, the argument must not be oversimplified. There are also 10 European countries with no evidence of the bias. There is one methodological issue, however, which further reinforces the findings on the existence of the financial centre bias. Recall that potential issuers in each country are identified as companies exceeding $€ 50 \mathrm{~m}$ in turnover. The threshold of $€ 50 \mathrm{~m}$ is adjusted to the country price level, but the difference in the level of prices between financial centres and the rest of the country is not accounted for. If higher prices in financial centres were accounted for, relatively more companies would be counted as large in the provinces, resulting in lower values of the GeoRep and PL/AL indices.

In table 5 it was assumed that New York is the financial centre of the USA. While New York is beyond doubt the financial capital of the USA, it may seem unsatisfactory to limit the analysis of geographical representativeness to a single centre in this continental size economy. Thus, figure 4 presents the GenRep Index for New York and seven other selected MSAs. Five MSAs included are the largest centres of the asset management industry: New York, Boston, San Francisco, Los Angeles, Denver (in the order of descending value of assets under management according to IFSL 2001). Chicago and Philadelphia are included as the $3^{\text {rd }}$ and $4^{\text {th }}$ largest MSA in terms of population, respectively, with their own claims to the role of financial centres. Finally, Detroit is added for comparison, as an MSA associated with manufacturing in contrast to financial services. The results show that all five asset management centres are better represented on stock markets than the other three MSAs. New York, in spite of being the financial centre of the country, lags behind the other asset management centres in terms of GenRep Index. The top three MSAs are the country's major centres of the venture capital industry, with San Francisco in the lead. Detroit, at the bottom of the graph, has very little to do with venture capital. The graph seems to reflect the extent to which each metropolitan region has fed public stock markets with companies, with the support of a powerful venture capital industry or the lack thereof. These results show that the financial centre bias can be strongly affected by the geography of venture capital industry. They also demonstrate how geographical representativeness interacts with sectoral representativeness, which is one of the topics discussed in the next section. 


\section{Figure 4. General Representativeness Index for selected major MSAs in the USA}

The graph presents the GenRep Index, i.e. the ratio of the number of publicly traded companies to the number of companies with turnover exceeding $€ 50 \mathrm{~m}$ in turnover, for selected major Metropolitan Statistical Areas (MSAs), calculated on the basis of data from ORBIS provided by the BVDEP.

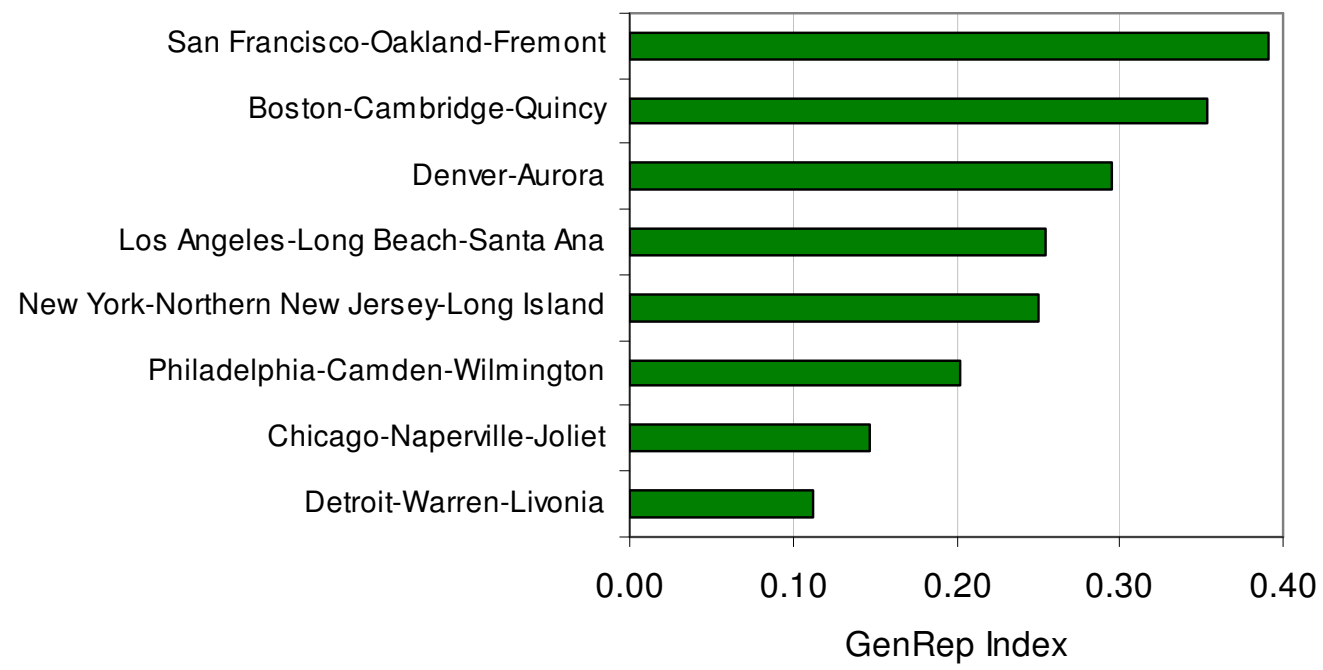

\section{Relationships between stock market representativeness indices}

This section explores relationships between different stock market representativeness indices. First, is the financial capital bias uncovered in the preceding section due to potential concentration of sectors with high level of stock market representation? Second, do countries with higher general representativeness exhibit higher geographical and sectoral representativeness, and weaker size bias? Finally, are there significant relationships between the role of widely held companies and various types of stock market representativeness?

\section{Geographical versus sectoral representativeness}

The analysis of geographical representativeness for the USA demonstrated that while New York is better represented on the stock markets than the rest of the country, at a finer level of analysis, the high technology centres of San Francisco, Boston, and Denver were even better represented. This triggers the question whether the financial centre bias prevailing in the USA, Japan, and more than two thirds of European countries, is not just the footprint of sectoral patterns of under- and overrepresentation. Does the geographical bias exist because financial centres are concentrations of highly represented sectors, such as financial services, or does the financial centre bias hold within sectors? Answering the question requires data that for each company identify its sector affiliation as well as location. Such data are available only for the UK. With London as the hub of global finance, this is however a very useful case, raising the 
question whether the UK stock markets exhibit a strong capital bias, because of the concentration of financial services firms in London.

In order to test the relationship between geographical and sectoral stock market representativeness for the UK the GeoRep Index was calculated separately for each of the 56 NACE sectors, for which there are any publicly traded UK firms. A company is considered as located in London, if it is headquartered in Greater London. Results show that the GeoRep Index is lower than one for 38, i.e. approx. $68 \%$ of sectors. Thus, in an absolute majority of sectors, companies from London possess an advantage over provincial companies in terms of their likelihood of being publicly traded. The London advantage varies greatly between individual sectors, even within financial services. For financial intermediation (mainly banks and leasing firms) the GeoRep Index is 0.99. In fact, while London hosts approx. two thirds of the UK publicly traded financial intermediation firms, it also hosts approx. two thirds of all large financial intermediation firms that exist in the UK. For insurance and pension funding the London advantage is strong, with the index vale of 0.45 ; however, for activities auxiliary to financial intermediation it is 2.25 , surprisingly indicating that provincial firms from this sector have better stock market representation than London based firms. Within hightechnology manufacturing, the GeoRep Index has values below one for manufacturing of radio, television, and communication equipment (0.73), as well as medical, precision, and optical instruments (0.84), but above one for office machinery and computers (1.70). Within high-technology knowledge intensive services, the index is below one for post and telecommunications (0.72), but above one for computer activities (1.03), and research and development (1.30). Considering large sectors, with large absolute numbers of firms, the highest levels of London advantage are found in the manufacturing of chemicals and the manufacturing of machinery and equipment, with the GeoRep Index values of 0.42 and 0.32 , respectively.

To summarise, in the UK the financial centre bias prevails in an absolute majority of sectors. Its existence is not determined by sectors concentrated in London having an advantage over sectors concentrated in the provinces in terms of their stock market participation. London bias is primarily about London itself. To be sure, the bias could still be affected by the concentration of financial services in London. This is not however, because the London financial services firms have better stock market representation than their provincial counterparts, but (as speculated in the preceding section) because of their role in creating a local business environment conducive to firms' participation in stock markets. While there are no data available to test these issues for other countries, the results for the UK reinforce the significance of the findings on geographical stock market representativeness.

\section{General versus size bias, sectoral, and geographical representativeness}

Analysis in this subsection involves the relationships between general stock market representativeness on one side and size bias, sectoral, and geographical representativeness on the other. The hypothesis is the following. Do economies, where publicly traded companies are generally more common (i.e. have higher GenRep and PL/AL indices), have stock markets which are less biased towards very large companies, and less biased in terms of their sectoral and geographical structure (i.e. have lower Size Bias, and higher SecRep and GeoRep indices)? Spearman's rho 
correlations between respective indices are used to test the hypothesis. For each index they are calculated for all 33, 23 non-transition, and 10 transition countries.

As demonstrated by the results in panel A of table 6, there is a very strong negative relationship between general representativeness and size bias. Economies, where publicly traded companies are more common, have stock markets that are definitely less biased towards very large companies. This finding is not trivial; given that only small fractions of very large and large companies are publicly traded (PL/AL and PVL/AVL indices are typically very low across countries). The relationships between the GenRep and PL/AL indices versus sectoral and geographical representativeness are positive but weak and not statistically significant. The only exception is the positive relationship between the GenRep and the GeoRep indices for non-transition countries. These results confirm the distinctive character of the three families of stock market representativeness indices.

\section{Table 6. General versus size bias, sectoral, and geographical representativeness}

The table presents Spearman's rho correlation coefficients between respective stock market representativeness indices, and their significance at $5 \%\left({ }^{*}\right)$ or $1 \%\left({ }^{* *}\right)$ confidence level. Data on GenRep, PL/AL, Size Bias, PWH/AL, and PWH/P are presented in table 1; on SecRep in table 3; and on GeoRep in table 5. Coefficients are calculated separately for all $(n=33)$, non-transition $(n=23)$, and transition $(n=10)$ countries.

\begin{tabular}{|c|c|c|c|c|c|c|c|}
\hline Index & Countries included & Size Bias & & SecRep & & GeoRep & \\
\hline \multicolumn{8}{|l|}{ Panel A } \\
\hline \multirow{3}{*}{ GenRep } & All & -0.60 & ** & 0.15 & & 0.33 & \\
\hline & Non-transition & -0.49 & * & 0.18 & & 0.42 & \multirow[t]{2}{*}{ * } \\
\hline & Transition & -0.88 & ** & 0.56 & & 0.54 & \\
\hline \multirow{3}{*}{ PL/AL } & All & -0.60 & ** & 0.13 & & 0.21 & \\
\hline & Non-transition & -0.56 & ** & 0.05 & & 0.34 & \\
\hline & Transition & -0.71 & * & 0.54 & & 0.49 & \\
\hline \multicolumn{8}{|l|}{ Panel B } \\
\hline \multirow{3}{*}{ PWH/AL } & All & -0.16 & & 0.46 & ** & 0.15 & \multirow{3}{*}{ ** } \\
\hline & Non-transition & -0.13 & & 0.41 & & 0.55 & \\
\hline & Transition & -0.39 & & 0.41 & & 0.44 & \\
\hline \multirow{3}{*}{$\mathrm{PWH} / \mathrm{P}$} & All & 0.32 & & 0.48 & ** & -0.09 & \multirow{3}{*}{ ** } \\
\hline & Non-transition & 0.28 & & 0.19 & & 0.53 & \\
\hline & Transition & -0.07 & & 0.22 & & -0.07 & \\
\hline
\end{tabular}

The role of corporate governance

Panel B of table 6 presents the correlation coefficients between size bias, sectoral, and geographical representativeness and the general representativeness indices focused on widely held publicly traded companies. The results seem exactly opposite to the results for the GenRep and PL/AL indices. First, the PWH/AL and PWH/P indices show no significant correlations with size bias. In contrast, there is evidence that the role of widely held publicly traded firms is significantly and positively related to both sectoral and geographical representativeness. This is an important finding, suggesting that 
countries where closely held publicly traded companies play a more important part in the economy as a whole, and among publicly traded companies in particular have less representative stock markets in terms of their sector structure and geography. As such, this result suggests a potential relationship between corporate governance and the structure of stock markets, whereby countries with less minority-shareholder friendly regimes have bigger gaps in terms of stock market representation between financial centres and the provinces, and between well and badly represented sectors. Perhaps the prevalence of companies controlled by insiders contributes to such gaps and biases, while the prevalence of widely held companies helps to overcome them? These issues should be addressed in further research. If the positive relationship between the role of widely held companies and sectoral and geographical stock market representativeness indeed holds, one major implication is that corporate law and other ongoing reforms in the European Union, aiming at more minority shareholder friendly corporate governance, may also promote more representative stock markets.

\section{Conclusions and implications}

The objective of this paper was to develop a new method for analysing stock market development by concentrating on the question whether and how stock markets represent the underlying economies. Three dimensions of stock market representativeness were identified: (i) general stock market representativeness, relating the number of publicly traded companies to the number of companies that could potentially be listed; (ii) sectoral stock market representativeness, relating the industrial structure of publicly traded companies to the industrial structure of the economy; and (iii) the geographical stock market representativeness, focusing on the location of publicly traded companies in the financial capital versus the provinces of a country. A series of stock market representativeness indices, exploring each of the three dimensions, was designed and applied to data on stock markets and economies of thirty one European countries as well Japan and the USA.

The main conclusion of the paper is that stock markets poorly represent the underlying economies. The first reason for poor representation is that publicly traded companies constitute an absolute minority of the total population of large companies. Even if we narrow down our interest to very large companies, those participating in public stock markets are still a minority. In this respect the level of stock market representativeness in Europe is much lower than in the USA and Japan. In Europe only 6\% of large and $11 \%$ of very large companies are publicly traded, in the USA and Japan these fractions are approximately twice and four times higher, respectively.

The second main reason why stock markets poorly represent the underlying economies is because certain types of companies are systematically under- and others systematically over-represented on stock markets. In Europe, the USA, and Japan alike, stock markets are strongly biased towards very large companies, towards high technology companies, and particularly high technology knowledge intensive services, as well as towards companies from financial centres. As such they are biased against smaller, although still large companies, against lower technology manufacturing and less knowledge intensive services, and against provincial companies. Notwithstanding these general findings, stock market representativeness varies considerably between 
individual countries, highlighting the significance of country-specific factors in the development of stock markets.

Important implications can be drawn from this paper for European policy-makers, researchers, as well as financial firms. In the field of strategic policy-making, overcoming the barriers faced by companies hitherto underrepresented on stock markets could help to sustain the dynamic growth of European stock markets in the future as well as their role in global stock markets. Of particular concern here is the financial centre bias. While size bias and sectoral bias may be driven by unavoidable fixed costs of public stock market participation, and industry-specific growth potential and corporate financial structure, high numbers of large, dynamic provincial companies not participating in stock markets appear less justified from a policy perspective, and represent an unused potential for the future development of European stock markets. Another finding of particular relevance for European policy-makers is that countries where closely held companies play a more important part in the economy appear to have less representative stock markets in terms of their sector structure and geography. The implication is that ongoing corporate law reforms in Europe, aiming at more minority shareholder friendly corporate governance may also promote more representative stock markets.

Implications for financial firms are at least threefold. First, stock market representativeness indices could be used to enhance the analysis of the markets of potential issuers conducted by stock exchanges and other stock market intermediaries. Second, the indices proposed in the paper should remind stock market analysts, that due to the low representativeness of stock markets, macroeconomic trends may poorly translate into fundamental factors affecting stock market performance. For example, a country's GDP growth figure can mean relatively little if the growth comes from sectors underrepresented on the country's stock market. Third, the financial centre bias uncovered in this paper implies a relatively low level of domestic geographical diversification of countries' stock markets and stock market indices, with possible implications for the level of volatility. This leads to a potential analogy with high sectoral concentration implying higher volatility of stock market returns (Roll 1992), and highlights the study of the relationship between domestic geographical diversification and stock market volatility as an area of future research.

The wide array of stock market representativeness indices designed and applied in this paper can be used by researchers in a number of ways. Indices focused on widely held companies can be used in empirical studies on corporate ownership and governance. General stock market representativeness indices could complement the MC/GDP ratios, commonly used in the studies on the relationship between financial development and economic growth. There are also many directions in which the research undertaken in this paper can be extended. The first strategy involves the analysis of the relationships between different types of representativeness. Size bias could be analysed by industry, and geographical representativeness could be further decomposed into pure sectoral and pure geographical effects. Second, while the role of R\&D intensity and venture capital industry has been discussed with respect to sectoral representativeness; and the role of asymmetric information, social networks, and culture with respect to geographical representativeness; a more comprehensive and robust investigation of the reasons for stock market biases is in order. Third, future research could examine factors behind the diversity of stock market representativeness across countries. Fourth, it could be 
possible to establish how stock market representativeness changes over time. Ultimately, it is hoped that the concept and the measures of stock market representativeness can improve our understanding of the relationship between stock markets and the 'real' economy.

\section{Bibliography}

Berglöf, E. , Pajuste, A. (2003) Corporate Governance in Central and Eastern Europe, in P. Cornelius and B. Kogut, Global Competitiveness and Corporate Governance, Oxford: Oxford University Press.

BVDEP (2006) Ownership database. Database description available from Bureau Van Dijk Electronic Publishing, www.bvdep.com.

Casey, J.-P., Lannoo, K. (2006) The MiFID Revolution. ECMI Policy Brief 3, Brussels: European Capital Markets Institute, available on www.eurocapitalmarkets.org.

Coval, J.D., Moskowitz, T.J. (1999) Home bias at home: local equity preference in domestic portfolios. The Journal of Finance 54 (6): 2045-2073.

ECMI (2006) European Capital Markets Institute Statistical Package 2006. Available on www.eurocapitalmarkets.org/files/ECMI\%20statistical\%20package\%20launch.pdf

Eurostat (2006) High tech industries and knowledge based services. Statistics in Focus: Science and Technology 13/2006.

Faccio, M., Lang, L.H.P. (2002) The ultimate ownership of Western European corporations. Journal of Financial Economics 65: 365-395.

Fama, E.F., French, K.R. (1998) Value versus growth: the international evidence. The Journal of Finance 53 (6): 1975-1999.

Grinblatt, M., Keloharju, M. (2001) How distance, language, and culture influence stockholdings and trades. The Journal of Finance 56 (3): 1053-1073.

Hau, H. (2001) Location matters: an examination of trading profits. The Journal of Finance 56 (5): 1959-1983.

Hong, H., Kubik, J.D., Stein, J.C. (2004) Social interaction and stock market participation. The Journal of Finance 59 (1) 137-163.

Huberman, G. (2001) Familiarity breeds investment. The Review of Financial Studies 14 (3): 659-680.

IFSL (2001) Fund management brief. Available from International Financial Services, London, www.ifsl.org.uk.

Kang, J. K., Stulz, R.M. (1997) Why is there a home bias? An analysis of foreign portfolio equity ownership in Japan. Journal of Financial Economics 46: 3-28. 
Knorr Cetina, K., Preda, A. (2005) The Sociology of Financial Markets. Oxford: Oxford University Press.

La Porta, R., Lopez-de-Silanes, F., Shleifer, A. (1999) Corporate ownership around the world. The Journal of Finance 54 (2): 471-517.

La Porta, R., Lopez-de-Silanes, F., Shleifer, A., Vishny, R.W. (1998) Law and finance. Journal of Political Economy 106 (6): 1113-1155.

La Porta, R., Lopez-de-Silanes, F., Shleifer, A., Vishny, R.W. (1996) Law and finance. Working Paper 5661. Cambridge, Mass.: NBER.

Malloy, C.J. (2005) The geography of equity analysis. The Journal of Finance 60 (2): 719-755.

OECD (2006) Purchasing power parities. Report available at www.oecd.org/std/ppp.

Oxera (2006) The cost of capital: an international comparison. Report available on www.cityoflondon.gov.uk/Corporation/business_city/research_statistics/research_publi cations.htm.

Pagano. M., Panetta, F., Zingales, L. (1998) Why do companies go public? An empirical analysis. The Journal of Finance 53 (1): 27-64.

Portes, R., Rey, H., Oh, Y. (2001) Information and capital flows: the determinants of transactions in financial assets. European Economic Review 45: 783-796.

Rajan, R., Zingales, L. (2003) The great reversals: the politics of financial development in the $20^{\text {th }}$ century. Journal of Financial Economics 69 (1): 5-50.

Roll, R. (1992) Industrial structure and the comparative behaviour of international stock market indices. The Journal of Finance 47 (1): 3-41.

Sarkissian, S., Schill, M.J. (2004) The overseas listing decision: new evidence of proximity preference. The Review of Financial Studies 17: 769-809.

Scottish Enterprise (2005) Pan-European perspectives: financial services international benchmarking report. Available on www.sfe.org.uk/knowledge/download/6.

Shleifer, A., Vishny, R.W. (1997) A survey of corporate governance. The Journal of Finance 52 (2): 737-783.

Stulz, R.M. (2005) Presidential address: the limits of financial globalization. The Journal of Finance 60 (4): 1595-1638.

Wójcik, D. (2007) Geography and the future of stock exchanges: between real and virtual space. Growth and Change (forthcoming). Working Paper version available from www.ssrn.com. 


\section{Appendix 1. Publicly traded companies by country at the end of September 2006}

For each country the appendix gives the total number of publicly traded companies, and a description of stock market segments included. The data were obtained from ORBIS by the BVDEP, and their consistency was tested by comparison to data from the World Federation of Exchanges, the Federation of European Stock Exchanges, and the websites of individual stock exchanges. In addition to the domestic segments stated, for each country the numbers include companies that are publicly traded only on a foreign exchange (for example the Irish companies traded on the Alternative Investment Market (AIM) of the London Stock Exchange, but not traded on the Irish Stock Exchange).

\begin{tabular}{|c|c|c|}
\hline Austria & 109 & Prime and Standard segment of the Wiener Börse \\
\hline Belgium & 159 & Eurolist and Marché Libre of the Euronext Brussels \\
\hline Bulgaria & 341 & $\begin{array}{l}\text { All companies listed on the Official and Unofficial Market of the Bulgarian } \\
\text { Stock Exchange }\end{array}$ \\
\hline Cyprus & 142 & All companies listed on the Cyprus Stock Exchange \\
\hline Czech Republic & 37 & All companies listed on the Prague Stock Exchange \\
\hline Denmark & 178 & $\begin{array}{l}\text { All companies listed on the OMX Copenhagen and the First North } \\
\text { Exchange }\end{array}$ \\
\hline Estonia & 16 & All companies listed on the OMX Tallinn \\
\hline Finland & 134 & All companies listed on OMX Helsinki. \\
\hline France & 946 & Eurolist, Alternext, and Marché Libre of the Euronext Paris \\
\hline Germany & 1014 & $\begin{array}{l}\text { Official Market and the Open Market (Freiverkehr i.e. the Regulated } \\
\text { Unofficial market) of the Deutsche Börse. }\end{array}$ \\
\hline Greece & 336 & $\begin{array}{l}\text { Big cap, mid and small cap, special financial character, and under } \\
\text { surveillance companies at the Athens Stock Exchange, but not suspended } \\
\text { listed companies. }\end{array}$ \\
\hline Hungary & 37 & $\begin{array}{l}\text { All companies with equities category A or B traded on the Budapest Stock } \\
\text { Exchange }\end{array}$ \\
\hline Iceland & 22 & All companies listed on the Iceland Stock Exchange \\
\hline Ireland & 114 & $\begin{array}{l}\text { The Official List and the Irish Enterprise Exchange (IEX) of the Irish Stock } \\
\text { Exchange. }\end{array}$ \\
\hline Italy & 292 & $\begin{array}{l}\text { All segments of the Borsa Italiana i.e. Blue Chip, Star, Standard, and } \\
\text { Mercato Expandi }\end{array}$ \\
\hline Latvia & 39 & All companies listed on the OMX Riga \\
\hline Liechtenstein & 2 & Liechtenstein domiciled companies listed on the SWX Swiss Exchange \\
\hline Lithuania & 43 & All companies listed on the OMX Vilnius \\
\hline Luxembourg & 49 & All companies listed on the Luxembourg Stock Exchange \\
\hline Malta & 11 & All companies listed on the official list of the Malta Stock Exchange \\
\hline Netherlands & 224 & All companies listed at Euronext Amsterdam \\
\hline Norway & 277 & $\begin{array}{l}\text { All segments of the Oslo Stock Exchange i.e. OBX, OB Match, OB } \\
\text { Standard, and OB New. }\end{array}$ \\
\hline Poland & 241 & $\begin{array}{l}\text { All companies listed on the Main and the Parallel Market of the Warsaw } \\
\text { Stock Exchange }\end{array}$ \\
\hline Portugal & 73 & All companies listed on the Euronext Lisbon \\
\hline Romania & 69 & All companies listed on the Bucharest Stock Exchange \\
\hline Slovakia & 251 & All companies with shares traded on the Bratislava Stock Exchange \\
\hline Slovenia & 81 & $\begin{array}{l}\text { All companies on the Official and Semi-Official Market of the Ljubljana } \\
\text { Stock Exchange }\end{array}$ \\
\hline Spain & 198 & $\begin{array}{l}\text { Companies traded on the Continuous Market and the Floor of the Bolsas y } \\
\text { Mercados Españoles (BME-X). SICAVs and SIMs are not included. }\end{array}$ \\
\hline Sweden & 395 & $\begin{array}{l}\text { All companies listed on the OMX Stockholm, the Nordic Growth Market, } \\
\text { and the First North Exchange }\end{array}$ \\
\hline Switzerland & 274 & $\begin{array}{l}\text { Main Market, Local Caps, Real Estate Companies and Investment } \\
\text { Companies of the SWX Swiss Exchange. }\end{array}$ \\
\hline UK & 2542 & All companies listed on the London Stock Exchange, including the AIM \\
\hline Japan & 3858 & $\begin{array}{l}\text { All companies traded on the Tokyo Stock Exchange, the JASDAQ, the } \\
\text { Nagoya SE, the Osaka Securities Exchange, the Sapporo Stock } \\
\text { Exchange, and the OTC Japan }\end{array}$ \\
\hline USA & 8861 & $\begin{array}{l}\text { The New York Stock Exchange, the NASDAQ National Market, the } \\
\text { NASDAQ Bulletin Board, the American Stock Exchange, and other OTC } \\
\text { markets }\end{array}$ \\
\hline
\end{tabular}




\section{Appendix 2. GDP, market capitalisation, and selected stock market development measures}

GDP data come from the following sources: for Liechtenstein from the economic data section of www.liechtenstein.li; for all other countries from World Development Indicators database, World Bank, 1 July 2006, http://siteresources.worldbank.org/DATASTATISTICS/Resources/GDP.pdf.

Domestic Market Capitalisation (MC) data come from: Bulgarian Stock Exchange, www.bse-sofia.be for Bulgaria; Bucharest Stock Exchange, www.bvb.ro for Romania; SWX Swiss Exchange, www.swx.com for Liechtenstein; NOREX, www.norex.com for Denmark, Estonia, Finland, Latvia, Lithuania, and Sweden; FESE, www.fese.be for Iceland, Czech Republic, and Slovakia; Euronext, www.euronext.com for Belgium, France, Netherlands, and Portugal; for all other countries from WFE, http://www.world-exchanges.org/WFE/home.asp?menu=378\&document=3552.

MC figures expressed in Euro were translated using the Euro/USD exchange rate of 1.1797 as at 30/12/2005 according to the European Central Bank. Antidirector rights come from La Porta, Lopez-de-Silanes, Shleifer, and Vishny (1998, pp.1130-31), and measure "how strongly the legal system favours shareholders (against managers) in the voting process" (La Porta et al. 1996, p.16).

Data in the third and the second last columns come from La Porta, Lopez-de-Silanes, and Shleifer (1999, p.492 and 494), and present the fraction of widely held firms in the sample of the 20 largest (according to MC at the end of 1995), and 10 smallest publicly traded firms with MC of at least $\$ 500$ million (at the end of 2005), respectively. The first sample is referred to as 'large firms' and the second as 'medium firms'. A firm is considered widely held if it has no shareholder whose total direct and indirect voting rights exceed $20 \%$.

The last column is based on Faccio and Lang (2002, p.379) and presents the percentage of widely held firms among publicly traded firms. While their detailed methodology of studying the ultimate ownership and control differs from that of La Porta et al., a widely held company is also defined as one with no shareholders controlling at least $20 \%$ of voting rights.

\begin{tabular}{|c|c|c|c|c|c|c|c|}
\hline Country & $\begin{array}{l}\text { GDP } 2005 \\
\text { (billion \$) }\end{array}$ & $\begin{array}{c}\text { Domestic MC } \\
\text { End } 2005 \text { (billion \$) }\end{array}$ & MC/GDP & Antidirector rights & $\begin{array}{l}\text { Fraction of } \\
\text { widely held } \\
\text { large firms }\end{array}$ & $\begin{array}{l}\text { Fraction of widely } \\
\text { held medium firms }\end{array}$ & $\begin{array}{l}\text { Percentage of } \\
\text { widely held firms }\end{array}$ \\
\hline Austria & 305 & 126 & 0.41 & 2 & 0.05 & 0.00 & 11.11 \\
\hline Belgium & 365 & 289 & 0.79 & 0 & 0.05 & 0.20 & 20.00 \\
\hline Bulgaria & 27 & 4 & 0.15 & $n / a$ & $\mathrm{n} / \mathrm{a}$ & $\mathrm{n} / \mathrm{a}$ & $\mathrm{n} / \mathrm{a}$ \\
\hline Cyprus & 15 & 7 & 0.43 & $\mathrm{n} / \mathrm{a}$ & $\mathrm{n} / \mathrm{a}$ & $\mathrm{n} / \mathrm{a}$ & $\mathrm{n} / \mathrm{a}$ \\
\hline Czech Republic & 122 & 37 & 0.30 & $n / a$ & $\mathrm{n} / \mathrm{a}$ & $\mathrm{n} / \mathrm{a}$ & $\mathrm{n} / \mathrm{a}$ \\
\hline Denmark & 254 & 184 & 0.72 & 2 & 0.40 & 0.30 & $\mathrm{n} / \mathrm{a}$ \\
\hline Estonia & 13 & 4 & 0.27 & $\mathrm{n} / \mathrm{a}$ & $\mathrm{n} / \mathrm{a}$ & $\mathrm{n} / \mathrm{a}$ & $\mathrm{n} / \mathrm{a}$ \\
\hline Finland & 193 & 239 & 1.24 & 3 & 0.35 & 0.20 & 28.68 \\
\hline France & 2,110 & 1,759 & 0.83 & 3 & 0.60 & 0.00 & 14.00 \\
\hline Germany & 2,782 & 1,221 & 0.44 & 1 & 0.50 & 0.10 & 10.37 \\
\hline Greece & 214 & 145 & 0.68 & 2 & 0.10 & 0.00 & $\mathrm{n} / \mathrm{a}$ \\
\hline Hungary & 109 & 33 & 0.30 & $\mathrm{n} / \mathrm{a}$ & $\mathrm{n} / \mathrm{a}$ & $\mathrm{n} / \mathrm{a}$ & $\mathrm{n} / \mathrm{a}$ \\
\hline Iceland & 15 & 28 & 1.89 & $n / a$ & $\mathrm{n} / \mathrm{a}$ & $\mathrm{n} / \mathrm{a}$ & $\mathrm{n} / \mathrm{a}$ \\
\hline Ireland & 196 & 114 & 0.58 & 4 & 0.65 & 0.63 & 62.32 \\
\hline Italy & 1,723 & 798 & 0.46 & 1 & 0.20 & 0.00 & 12.98 \\
\hline Latvia & 16 & 3 & 0.16 & $n / a$ & $\mathrm{n} / \mathrm{a}$ & $\mathrm{n} / \mathrm{a}$ & $\mathrm{n} / \mathrm{a}$ \\
\hline
\end{tabular}




\begin{tabular}{|c|c|c|c|c|c|c|c|}
\hline Country & $\begin{array}{l}\text { GDP } 2005 \\
\text { (billion \$) }\end{array}$ & $\begin{array}{c}\text { Domestic MC } \\
\text { End } 2005 \text { (billion \$) }\end{array}$ & $\mathrm{MC} / \mathrm{GDP}$ & Antidirector rights & $\begin{array}{l}\text { Fraction of } \\
\text { widely held } \\
\text { large firms }\end{array}$ & $\begin{array}{l}\text { Fraction of widely } \\
\text { held medium firms }\end{array}$ & $\begin{array}{c}\text { Percentage of } \\
\text { widely held firms }\end{array}$ \\
\hline Liechtenstein & 3 & 3 & 1.00 & $n / a$ & $\mathrm{n} / \mathrm{a}$ & $n / a$ & $\mathrm{n} / \mathrm{a}$ \\
\hline Lithuania & 26 & 8 & 0.24 & $\mathrm{n} / \mathrm{a}$ & $\mathrm{n} / \mathrm{a}$ & $\mathrm{n} / \mathrm{a}$ & $\mathrm{n} / \mathrm{a}$ \\
\hline Luxembourg & 34 & 51 & 1.50 & $\mathrm{n} / \mathrm{a}$ & $\mathrm{n} / \mathrm{a}$ & $\mathrm{n} / \mathrm{a}$ & $\mathrm{n} / \mathrm{a}$ \\
\hline Malta & 6 & 4 & 0.73 & $\mathrm{n} / \mathrm{a}$ & $\mathrm{n} / \mathrm{a}$ & $\mathrm{n} / \mathrm{a}$ & $\mathrm{n} / \mathrm{a}$ \\
\hline Netherlands & 595 & 593 & 1.00 & 2 & 0.30 & 0.10 & $\mathrm{n} / \mathrm{a}$ \\
\hline Norway & 284 & 191 & 0.67 & 4 & 0.25 & 0.20 & 36.77 \\
\hline Poland & 299 & 94 & 0.31 & $\mathrm{n} / \mathrm{a}$ & $\mathrm{n} / \mathrm{a}$ & $\mathrm{n} / \mathrm{a}$ & $\mathrm{n} / \mathrm{a}$ \\
\hline Portugal & 173 & 67 & 0.39 & 3 & 0.10 & 0.00 & 21.84 \\
\hline Romania & 99 & 18 & 0.18 & $\mathrm{n} / \mathrm{a}$ & $\mathrm{n} / \mathrm{a}$ & $\mathrm{n} / \mathrm{a}$ & $\mathrm{n} / \mathrm{a}$ \\
\hline Slovakia & 46 & 4 & 0.09 & $\mathrm{n} / \mathrm{a}$ & $\mathrm{n} / \mathrm{a}$ & $\mathrm{n} / \mathrm{a}$ & $\mathrm{n} / \mathrm{a}$ \\
\hline Slovenia & 34 & 8 & 0.23 & $\mathrm{n} / \mathrm{a}$ & $\mathrm{n} / \mathrm{a}$ & $\mathrm{n} / \mathrm{a}$ & $n / a$ \\
\hline Spain & 1,124 & 960 & 0.85 & 4 & 0.35 & 0.00 & 26.42 \\
\hline Sweden & 354 & 438 & 1.24 & 3 & 0.25 & 0.10 & 39.18 \\
\hline Switzerland & 366 & 935 & 2.55 & 2 & 0.60 & 0.50 & 27.57 \\
\hline UK & 2,193 & 3,058 & 1.39 & 5 & 1.00 & 0.60 & 63.08 \\
\hline EU 15 & 12,615 & 10,043 & 0.80 & $\mathrm{n} / \mathrm{a}$ & $\mathrm{n} / \mathrm{a}$ & $\mathrm{n} / \mathrm{a}$ & $\mathrm{n} / \mathrm{a}$ \\
\hline EU Transition 10 & 790 & 212 & 0.27 & $\mathrm{n} / \mathrm{a}$ & $\mathrm{n} / \mathrm{a}$ & $\mathrm{n} / \mathrm{a}$ & $\mathrm{n} / \mathrm{a}$ \\
\hline Europe & 14,094 & 11,423 & 0.81 & $\mathrm{n} / \mathrm{a}$ & $\mathrm{n} / \mathrm{a}$ & $\mathrm{n} / \mathrm{a}$ & $\mathrm{n} / \mathrm{a}$ \\
\hline Japan & 4,506 & 7,543 & 1.67 & 4 & 0.90 & 0.30 & $\mathrm{n} / \mathrm{a}$ \\
\hline USA & 12,455 & 17,001 & 1.36 & 5 & 0.80 & 0.90 & $\mathrm{n} / \mathrm{a}$ \\
\hline
\end{tabular}




\section{Appendix 3. NACE codes and the OECD/Eurostat classification of economic activities}

The appendix presents economic sectors and their NACE Rev.1.1. codes, as used within the European Union, as well as their OECD/Eurostat classification based on R\&D intensity (Eurostat 2006). Column P/AL reports the ratio of the number of publicly traded companies to the number of all large companies in a given sector, calculated on the basis of ORBIS database provided by the BVDEP. The OECD/Eurostat classification focuses on manufacturing and services, leaving all other economic activities unclassified. The appendix presents only these sectors for which at least one company with turnover exceeding $€ 50 \mathrm{~m}$ is recorded in the sample countries. This implies that categories: private households (code P95), undifferentiated goods (P96), undifferentiated services (P97). and extra-territorial oraanisations (Q99) are omitted.

\begin{tabular}{|c|c|c|c|}
\hline $\begin{array}{l}\text { NACE } \\
\text { code }\end{array}$ & Sector name & $\mathrm{P} / \mathrm{AL}$ & $\begin{array}{l}\text { OECD/Eurostat } \\
\text { classification }\end{array}$ \\
\hline A1 & Agriculture and hunting & 0.17 & \multirow{8}{*}{ Not classified } \\
\hline $\mathrm{A} 2$ & Forestry and logging & 0.30 & \\
\hline B5 & Fishing, fish hatcheries/farms & 0.68 & \\
\hline CA10 & Mining of coal and lignite & 0.18 & \\
\hline CA11 & Extraction of petroleum and gas & 0.51 & \\
\hline CA12 & Mining of uranium and thorium & 0.75 & \\
\hline CB13 & Mining of metal ores & 1.38 & \\
\hline CB14 & Other mining and quarrying & 0.38 & \\
\hline DA15 & Manufacture of food products and beverages & 0.15 & \multirow{8}{*}{$\begin{array}{l}\text { Low technology } \\
\text { manufacturing }\end{array}$} \\
\hline DA16 & Manufacture of tobacco products & 0.22 & \\
\hline DB17 & Manufacture of textiles & 0.34 & \\
\hline DB18 & Manufacture of wearing apparel & 0.35 & \\
\hline DC19 & Tanning and dressing of leather & 0.36 & \\
\hline DD20 & Manufacture of wood and cork & 0.15 & \\
\hline DE21 & Manufacture of pulp and paper & 0.16 & \\
\hline DE22 & Publishing and printing & 0.20 & \\
\hline DF23 & Manufacture of coke, refined petroleum products, and nuclear fuel & 0.16 & Med. low tech. m. \\
\hline DG24 & Manufacture of chemicals and chemical products & 0.34 & Med. h. tech. m. \\
\hline $\mathrm{DH} 25$ & Manufacture of rubber and plastic products & 0.16 & \multirow{4}{*}{$\begin{array}{l}\text { Medium low } \\
\text { technology } \\
\text { manufacturing }\end{array}$} \\
\hline DI26 & Manufacture of other non-metallic mineral products & 0.20 & \\
\hline DJ27 & Manufacture of basic metals & 0.22 & \\
\hline DJ28 & Manufacture of metal products & 0.16 & \\
\hline DK29 & Manufacture of machinery & 0.25 & Med. h. tech. m. \\
\hline DL30 & Manufacture of office machinery and computers & 0.57 & High technology m. \\
\hline DL31 & Manufacture of electrical machinery & 0.26 & Med. h. tech. m. \\
\hline DL32 & Manufacture of radio, television, and communication eq. and app. & 0.65 & High technology m. \\
\hline DL33 & Manufacture of medical, precision, and optical instruments & 0.58 & High technology m. \\
\hline DM34 & Manufacture of motor vehicles & 0.16 & \multirow{2}{*}{ Med. h. tech. m. } \\
\hline DM35 & Manufacture of other transport equipment & 0.22 & \\
\hline DN36 & Manufacture of furniture & 0.28 & \multirow{2}{*}{$\begin{array}{l}\text { Low technology } \\
\text { manufacturing }\end{array}$} \\
\hline DN37 & Recycling & 0.02 & \\
\hline E40 & Electricity, gas, steam, and hot water supply & 0.14 & \multirow{3}{*}{ Not classified } \\
\hline E41 & Collection, purification, and distribution of water & 0.17 & \\
\hline $\mathrm{F} 45$ & Construction & 0.10 & \\
\hline
\end{tabular}




\begin{tabular}{|c|c|c|c|}
\hline $\begin{array}{l}\text { NACE } \\
\text { code }\end{array}$ & Sector name & $\mathrm{P} / \mathrm{AL}$ & $\begin{array}{l}\text { OECD/Eurostat } \\
\text { classification }\end{array}$ \\
\hline G50 & Sale, maintenance, and repair of motor vehicles & 0.03 & \multirow{5}{*}{$\begin{array}{l}\text { Less knowledge } \\
\text { intensive services }\end{array}$} \\
\hline G51 & Wholesale and commission trade & 0.06 & \\
\hline G52 & Retail trade; repair of personal and household goods & 0.15 & \\
\hline H55 & Hotels and restaurants & 0.31 & \\
\hline 160 & Land transport; transport via pipelines & 0.13 & \\
\hline 161 & Water transport & 0.21 & \multirow{2}{*}{$\begin{array}{l}\text { Other knowledge } \\
\text { intensive services }\end{array}$} \\
\hline 162 & Air transport & 0.18 & \\
\hline 163 & Supporting transport activities; travel agencies & 0.10 & Less know. int. s. \\
\hline 164 & Post and telecommunications & 0.50 & H. tech. know. int. s. \\
\hline J65 & Financial intermediation, except insurance and pension funding & 0.37 & \multirow{5}{*}{$\begin{array}{l}\text { Other knowledge } \\
\text { intensive services }\end{array}$} \\
\hline J66 & Insurance and pension funding, except compulsory social security & 0.06 & \\
\hline J67 & Activities auxiliary to financial intermediation & 0.80 & \\
\hline K70 & Real estate activities & 0.20 & \\
\hline K71 & Renting of machinery and equipment & 0.17 & \\
\hline K72 & Computer and related activities & 0.75 & \multirow{2}{*}{$\begin{array}{l}\text { H. tech. knowledge } \\
\text { intensive services }\end{array}$} \\
\hline K73 & Research and development & 0.54 & \\
\hline K74 & Other business activities & 0.15 & Other know. int. s. \\
\hline $\mathrm{L} 75$ & Public administration and defense; compulsory social security & 0.04 & Less know. int. s. \\
\hline M80 & Education & 0.44 & \multirow{2}{*}{ Other know. int. s. } \\
\hline N85 & Health and social work & 0.09 & \\
\hline 090 & Sewage and refuse disposal & 0.22 & \multirow{2}{*}{$\begin{array}{l}\text { Less knowledge } \\
\text { intensive services }\end{array}$} \\
\hline 091 & Activities of membership organisations & 0.02 & \\
\hline O92 & Recreational, cultural and sporting activities & 0.29 & Other know. int. s. \\
\hline 093 & Other service activities & 0.20 & Less know. int. s. \\
\hline
\end{tabular}


Appendix 4. Definition of the spatial scope of analysed cities

\begin{tabular}{|c|c|c|}
\hline Austria & Vienna & The State of Vienna \\
\hline Belgium & Brussels & The Brussels Capital Region \\
\hline Bulgaria & Sofia & The Capital Municipality of Sofia \\
\hline Cyprus & Nicosia & Nicosia Municipality \\
\hline Czech Republic & Prague & The Capital City of Prague \\
\hline Denmark & Copenhagen & Metropolitan Copenhagen - Storkøbenhavn \\
\hline Estonia & Tallinn & Tallinn Municipality \\
\hline Finland & Helsinki & Helsinki Metropolitan Area \\
\hline France & Paris & Île-de-France \\
\hline \multirow[t]{4}{*}{ Germany } & Berlin & The State of Berlin \\
\hline & Düsseldorf & The Urban District (Stadkreise) of Düsseldorf \\
\hline & Frankfurt am Main & The Urban District of Frankfurt am Main \\
\hline & Munich & The Urban District of Munich \\
\hline Greece & Athens & Athens-Piraeus Super-Prefecture \\
\hline Hungary & Budapest & The Capital City of Budapest \\
\hline Iceland & Reykjavik & The Capital Region of Reykjavík \\
\hline Ireland & Dublin & County Dublin \\
\hline \multirow[t]{3}{*}{ Italy } & Milan & The Province of Milan \\
\hline & Rome & The Province of Rome \\
\hline & Turin & The Province of Turin \\
\hline Latvia & Riga & Riga District \\
\hline Liechtenstein & Vaduz & The Municipality of Vaduz \\
\hline Lithuania & Vilnius & The Vilnius City Municipality \\
\hline Luxembourg & Luxembourg & Luxembourg City \\
\hline Malta & Valetta & The Municipality of Valletta \\
\hline \multirow[t]{2}{*}{ Netherlands } & Amsterdam & The Municipality of Amsterdam \\
\hline & Rotterdam & The Municipality of Rotterdam \\
\hline Norway & Oslo & Greater Oslo Region \\
\hline Poland & Warsaw & The Capital Municipality of Warsaw \\
\hline \multirow[t]{2}{*}{ Portugal } & Lisbon & Greater Lisbon \\
\hline & Porto & Greater Porto \\
\hline Romania & Bucharest & The Municipality of Bucharest \\
\hline Slovakia & Bratislava & The Municipality of Bratislava \\
\hline Slovenia & Ljubljana & The Municipality of Ljubljana \\
\hline \multirow[t]{2}{*}{ Spain } & Barcelona & The county of Barcelona - Comarca el Barcelonès \\
\hline & Madrid & The Autonomous Community of Madrid \\
\hline Sweden & Stockholm & Greater Stockholm - Storstockholm \\
\hline \multirow[t]{3}{*}{ Switzerland } & Basel & The Cantons of Basel City and Basel-Land \\
\hline & Geneva & The Canton of Geneva \\
\hline & Zürich & The Canton of Zürich \\
\hline UK & London & Greater London \\
\hline Japan & Tokyo & Tokyo Prefecture \\
\hline \multirow[t]{8}{*}{ USA } & New York & New York-Northern New Jersey-Long Island MSA \\
\hline & Los Angeles & Los Angeles-Long Beach-Santa Ana MSA \\
\hline & Chicago & Chicago-Naperville-Joliet MSA \\
\hline & Philadelphia & Philadelphia-Camden-Wilmington MSA \\
\hline & Detroit & Detroit-Warren-Livonia MSA \\
\hline & Boston & Boston-Cambridge-Quincy MSA \\
\hline & San Francisco & San Francisco-Oakland-Fremont MSA \\
\hline & Denver & Denver-Aurora Metropolitan Statistical Area (MSA) \\
\hline
\end{tabular}

